Article

\title{
A Kind of Variation Symmetry: Tarski Associative Groupoids (TA-Groupoids) and Tarski Associative Neutrosophic Extended Triplet Groupoids (TA-NET-Groupoids)
}

\author{
Xiaohong Zhang ${ }^{1, *}$, Wangtao Yuan ${ }^{1}$, Mingming Chen ${ }^{1}$ and Florentin Smarandache ${ }^{2}$ (I) \\ 1 Department of Mathematics, Shaanxi University of Science \& Technology, Xi'an 710021, China; \\ 1809007@sust.edu.cn (W.Y.); chenmingming@sust.edu.cn (M.C.) \\ 2 Department of Mathematics, University of New Mexico, Gallup, NM 87301, USA; smarand@unm.edu \\ * Correspondence: zhangxiaohong@sust.edu.cn
}

Received: 21 February 2020; Accepted: 9 April 2020; Published: 2 May 2020

check for updates

\begin{abstract}
The associative law reflects symmetry of operation, and other various variation associative laws reflect some generalized symmetries. In this paper, based on numerous literature and related topics such as function equation, non-associative groupoid and non-associative ring, we have introduced a new concept of Tarski associative groupoid (or transposition associative groupoid (TA-groupoid)), presented extensive examples, obtained basic properties and structural characteristics, and discussed the relationships among few non-associative groupoids. Moreover, we proposed a new concept of Tarski associative neutrosophic extended triplet groupoid (TA-NET-groupoid) and analyzed related properties. Finally, the following important result is proved: every TA-NET-groupoid is a disjoint union of some groups which are its subgroups.
\end{abstract}

Keywords: Tarski associative groupoid (TA-groupoid); TA-NET-groupoid; semigroup; subgroup

\section{Introduction}

Generally, group and semigroup [1-5] are two basic mathematical concepts which describe symmetry. As far as we know the term semigroup was firstly introduced in 1904 in a French book (see book review [1]). A semigroup is called right commutative if it satisfies the identity $a^{*}\left(x^{*} y\right)=a^{*}\left(y^{*} x\right)$ [4]. When we combine right commutative with associative law, we can get the identity:

$$
\left(x^{*} y\right) * z=x^{*}\left(z^{*} y\right) \text { (Tarski associative law). }
$$

In this study we focused on the non-associative groupoid satisfying Tarski associative law (it is also called transposition associative law), and this kind of groupoid is called Tarski associative groupoid (TA-groupoid). From a purely algebraic point of view, these structures are interesting. They produce innovative ideas and methods that help solve some old algebraic problems.

In order to express the general symmetry and algebraic operation laws which are similar with the associative law, scholars have studied various generalized associative laws. As early as in 1924, Suschkewitsch [6] studied the following generalized associative law (originally called "Postulate A"):

$$
(x * a) * b=x^{*} c,
$$

where the element $c$ depended upon the element $a$ and $b$ only, and not upon $x$. Apparently, the associative law is a special case of this Postulate A when $c=a^{*} b$, and Tarski associative law explained 
above is also a special case of this Postulate A when $c=b^{*} a$. This fact shows that Tarski associative groupoid (TA-groupoid) studied in our research is a natural generalization of the semigroup. At the same time, Hosszu studied the function equations satisfying Tarski associative law in 1954 (see [7-9]); Thedy [10] studied rings satisfying $x(y z)=(y x) z$, and it is symmetric to Tarski associative groupoid, since defining $x^{*} y=y x, x(y z)=(y x) z$ is changed to $\left(z^{*} y\right)^{*} x=z^{*}\left(x^{*} y\right)$; Phillips (see the Table 12 in [11]) and Pushkashu [12] also referred to Tarski associative law. These facts show that the systematic study of Tarski associative groupoid (TA-groupoid) is helpful to promote the study of non-associative rings and other non-associative algebraic systems.

In recent years, a variety of non-associative groupoids have been studied in depth (it should be noted that the term "groupoid" has many different meanings, such as the concept in category theory and algebraic topology, see [13]). An algebraic structure midway between a groupoid and a commutative semigroup appeared in 1972, Kazim and Naseeruddin [14] introduced the concept of left almost semigroup (LA-semigroup) as a generalization of commutative semigroup and it is also called Abel-Grassmann's groupoid (or simply AG-groupoid). Many different aspects of AG-groupoids have been studied in [15-22]. Moreover, Mushtaq and Kamran [19] in 1989 introduced the notion of $\mathrm{AG}^{*}$-groupoids: one AG-groupoid $\left(S,{ }^{*}\right)$ is called $\mathrm{AG}^{*}$-groupoid if it satisfies

$$
\left(x^{*} y\right)^{*} z=y^{*}(x * z) \text {, for any } x, y, z \in S .
$$

Obviously, when we reverse the above equation, we can get $\left(z^{*} x\right)^{*} y=z^{*}\left(y^{*} x\right)$, which is the Tarski associative law (transposition associative law). In [23], a new kind of non-associative groupoid (cyclic associative groupoid, shortly, CA-groupoid) is proposed, and some interesting results are presented.

Moreover, this paper also involves with the algebraic system "neutrosophic extended triplet group", which has been widely studied in recent years. The concept of neutrosophic extended triplet group (NETG) is presented in [24], and the close relationship between NETGs and regular semigroups has been established [25]. Many other significant results on NETGs and related algebraic systems can be found, see $[25,26]$. In this study, combining neutrosophic extended triplet groups (NETGs) and Tarski associative groupoids (TA-groupoids), we proposed the concept of Tarski associative neutrosophic extended triplet groupoid (TA-NET-groupoid).

This paper has been arranged as follows. In Section 2, we give some definitions and properties on groupoid, CA-groupoid, AG-groupoid and NETG. In Section 3, we propose the notion of Tarski associative groupoid (TA-groupoid), and show some examples. In Section 4, we study its basic properties, and, moreover, analyze the relationships among some related algebraic systems. In Section 5, we introduce the new concept of Tarski associative NET-groupoid (TA-NET-groupoid) and weak commutative TA-NET-groupoid (WC-TA-NET-Groupoid), investigate basic properties of TANET-groupoids and weak commutative TA-NET-groupoids (WC-TA-NET-Groupoids). In Section 6, we prove a decomposition theorem of TA-NET-groupoid. Finally, Section 7 presents the summary and plans for future work.

\section{Preliminaries}

In this section, some notions and results about groupoids, AG-groupoids, CA-groupoids and neutrosophic triplet groups are given. A groupoid is a pair $\left(S,{ }^{*}\right)$ where $S$ is a non-empty set with a binary operation *. Traditionally, when the * operator is omitted, it will not be confused. Suppose $\left(S,{ }^{*}\right)$ is a groupoid, we define some concepts as follows:

(1) $\forall a, b, c \in S, a^{*}\left(b^{*} c\right)=a^{*}\left(c^{*} b\right), S$ is called right commutative; if $\left(a^{*} b\right)^{*} c=\left(b^{*} a\right)^{*} c$, $S$ is called left commutative. When $S$ is right and left commutative, then it is called bi-commutative groupoid.

(2) If $a^{2}=a(a \in S)$, the element $a$ is called idempotent.

(3) If for all $x, y \in S, a^{*} x=a^{*} y \Rightarrow x=y\left(x^{*} a=y^{*} a \Rightarrow x=y\right)$, the element $a \in S$ is left cancellative (respectively right cancellative). If an element is a left and right cancellative, the element is 
cancellative. If ( $\forall a \in S) a$ is left (right) cancellative or cancellative, then $S$ is left (right) cancellative or cancellative.

(4) If $\forall a, b, c \in S, a^{*}\left(b^{*} c\right)=\left(a^{*} b\right)^{*} c, S$ is called semigroup. If $\forall a, b \in S, a^{*} b=b^{*} a$, then a semigroup $\left(S,{ }^{*}\right)$ is commutative.

(5) If $\forall a \in S, a^{2}=a$, a semigroup $(S, *)$ is called a band.

Definition 1. ([14,15]) Assume that $\left(S,{ }^{*}\right)$ is a groupoid. If $S$ satisfying the left invertive law: $\forall a, b, c \in S$, $\left(a^{*} b\right)^{*} c=\left(c^{*} b\right)^{*} a$. $S$ is called an Abel-Grassmann's groupoid (or simply AG-groupoid).

Definition 2. ([21,22]) Let $\left(S,{ }^{*}\right)$ be an AG-groupoid, for all $a, b, c \in S$.

(1) If $\left(a^{*} b\right)^{*} c=b^{*}\left(a^{*} c\right)$, then $S$ is called an $A G^{*}$-groupoid.

(2) If $a^{*}\left(b^{*} c\right)=b^{*}\left(a^{*} c\right)$, then $S$ is called an $A G^{* *}$-groupoid.

(3) If $a^{*}\left(b^{*} c\right)=c^{*}\left(a^{*} b\right)$, then $S$ is called a cyclic associative AG-groupoid (or CA-AG-groupoid).

Definition 3. [23] Let ( $\left.S,{ }^{*}\right)$ be a groupoid. $S$ is called a cyclic associative groupoid (shortly, $C A$-groupoid), if $S$ satisfying the cyclic associative law: $\forall a, b, c \in S, a^{*}\left(b^{*} c\right)=c^{*}\left(a^{*} b\right)$.

Proposition 1. [23] Let (S, *) be a CA-groupoid, then:

(1) For any $a, b, c, d, x, y \in S,(a * b) *(c * d)=(d * a) *(c * b)$;

(2) For any $a, b, c, d, x, y \in S,(a * b) *\left(\left(c^{*} d\right) *(x * y)\right)=(d * a) *((c * b) *(x * y))$.

Definition 4. ([24,26]) Suppose $S$ be a non-empty set with the binary operation *. If for any $a \in S$, there is a neutral " $a$ " (denote by neut( $(a)$ ), and the opposite of " $a$ " (denote by anti $(a)$ ), such that neut $(a) \in S$, anti $(a) \in S$, and: $a *$ neut $(a)=\operatorname{neut}(a) * a=a ; a * \operatorname{anti}(a)=\operatorname{anti}(a) * a=$ neut $(a)$. Then, $S$ is called a neutrosophic extended triplet set.

Note: For any $a \in S$, neut( $a$ ) and anti(a) may not be unique for the neutrosophic extended triplet set $(S, *)$. To avoid ambiguity, we use the symbols $\{$ neut $(a)\}$ and $\{a n t i(a)\}$ to represent the sets of neut $(a)$ and anti(a), respectively.

Definition 5. $([24,26])$ Let $(S, *)$ be a neutrosophic extended triplet set. Then, $S$ is called a neutrosophic extended triplet group (NETG), if the following conditions are satisfied:

(1) $(S, *)$ is well-defined, that is, for any $a, b \in S, a * b \in S$.

(2) $\left(S,{ }^{*}\right)$ is associative, that is, for any $a, b, c \in S,(a * b){ }^{*} c=a *(b * c)$.

A NETG $S$ is called a commutative NETG if $a^{*} b=b^{*} a, \forall a, b \in S$.

Proposition 2. ([25]) Let $\left(S,{ }^{*}\right)$ be a NETG. Then $(\forall a \in S)$ neut $(a)$ is unique.

Proposition 3. ([25]) Let $\left(S,{ }^{*}\right)$ be a groupoid. Then $S$ is a NETG if and only if it is a completely regular semigroup.

\section{Tarski Associative Groupoids (TA-Groupoids)}

Definition 6. Let $(S, *)$ be a groupoid. $S$ is called a Tarski associative groupoid (shortly, TA-groupoid), if $S$ satisfying the Tarski associative law (it is also called transposition associative law): $\left(a^{*} b\right)^{*} c=a^{*}\left(c^{*} b\right), \forall a$, $b, c \in S$. 
The following examples depict the wide existence of TA-groupoids.

Example 1. For the regular hexagon as shown in Figure 1, denote $S=\left\{\theta, G, G^{2}, G^{3}, G^{4}, G^{5}\right\}$, where $G, G^{2}, G^{3}$, $G^{4}, G^{5}$ and $\theta$ represent rotation $60,120,180,240,300$ and 360 degrees clockwise around the center, respectively.

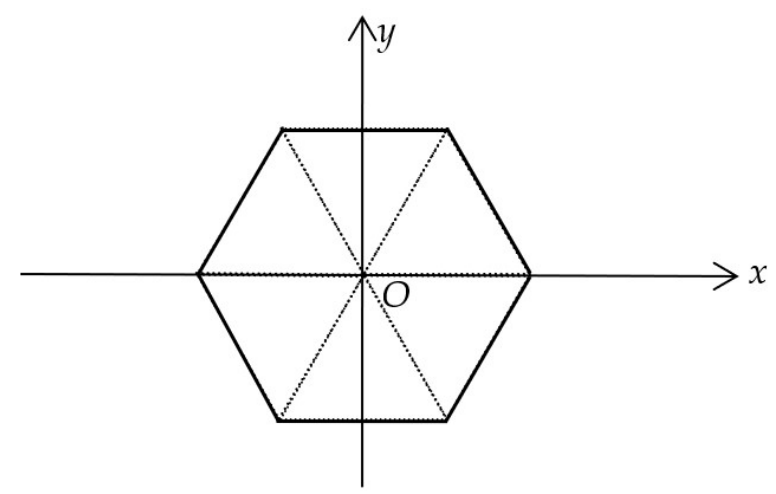

Figure 1. Regular hexagon.

Define the binary operation $\circ$ as a composition of functions in $S$, that is, $\forall U, V \in S, U \circ V$ is that the first transforming $V$ and then transforming $U$. Then $(S, \circ)$ is a TA-groupoid (see Table 1$)$.

Table 1. Cayley table on $S=\left\{\theta, G, G^{2}, G^{3}, G^{4}, G^{5}\right\}$.

\begin{tabular}{ccccccc}
\hline$\circ$ & $\boldsymbol{\theta}$ & $\boldsymbol{G}$ & $G^{2}$ & $G^{3}$ & $G^{4}$ & $G^{5}$ \\
\hline $\boldsymbol{\theta}$ & $\theta$ & $G$ & $G^{2}$ & $G^{3}$ & $G^{4}$ & $G^{5}$ \\
$\boldsymbol{G}$ & $G$ & $G^{2}$ & $G^{3}$ & $G^{4}$ & $G^{5}$ & $\theta$ \\
$G^{2}$ & $G^{2}$ & $G^{3}$ & $G^{4}$ & $G^{5}$ & $\theta$ & $G$ \\
$G^{3}$ & $G^{3}$ & $G^{4}$ & $G^{5}$ & $\theta$ & $G$ & $G^{2}$ \\
$G^{4}$ & $G^{4}$ & $G^{5}$ & $\theta$ & $G$ & $G^{2}$ & $G^{3}$ \\
$G^{5}$ & $G^{5}$ & $\theta$ & $G$ & $G^{2}$ & $G^{3}$ & $G^{4}$ \\
\hline
\end{tabular}

Example 2. Let $S=[n, 2 n]$ (real number interval, $n$ is a natural number), $\forall x, y \in S$. Define the multiplication *by

$$
x * y= \begin{cases}x+y-n, & \text { if } x+y \leq 3 n \\ x+y-2 n, & \text { if } x+y>3 n\end{cases}
$$

Then $\left(S,{ }^{*}\right)$ is a TA-groupoid, since it satisfies $\left(x^{*} y\right) * z=x^{*}\left(z^{*} y\right), \forall x, y, z \in S$, the proof is as follows:

Case 1: $x+y+z-n \leq 3 n$. It follows that $y+z \leq x+y+z-n \leq 3 n$ and $x+y \leq x+y+z-n \leq 3 n$. Then $\left(x^{*} y\right)^{*} z=(x+y-n)^{*} z=x+y+z-2 n=x *(z+y-n)=x^{*}\left(z^{*} y\right)$.

Case 2: $x+y+z-n>3 n, y+z \leq 3 n$ and $x+y \leq 3 n$. Then $\left(x^{*} y\right)^{*} z=(x+y-n)^{*} c=x+y+z-3 n=$ $x^{*}(z+y-n)=x^{*}\left(z^{*} y\right)$.

Case 3: $x+y+z-n>3 n, y+z \leq 3 n$ and $x+y>3 n$. It follows that $x+y+z-2 n \leq x+3 n-2 n=x+n$ $\leq 3 n$. Then $\left(x^{*} y\right){ }^{*} z=(x+y-2 n){ }^{*} c=x+y+z-3 n=x^{*}(z+y-n)=x^{*}\left(z^{*} y\right)$.

Case 4: $x+y+z-n>3 n, y+z>3 n$ and $x+y \leq 3 n$. It follows that $x+y+z-2 n \leq 3 n+c-2 n=z+$ $n \leq 3 n$. Then $\left(x^{*} y\right)^{*} z=(x+y-n)^{*} z=x+y+z-3 n=x^{*}(z+y-2 n)=x^{*}(z * y)$.

Case 5: $x+y+z-n>3 n, y+z>3 n$ and $x+y>3 n$. When $x+y+c-2 n \leq 3 n,\left(x^{*} y\right) * z=(x+y-2 n)$ ${ }^{*} z=x+y+z-3 n=x^{*}(z+y-2 n)=x^{*}\left(z^{*} y\right)$; When $x+y+z-2 n>3 n,\left(x^{*} y\right)^{*} z=(x+y-2 n)^{*} z=x+$ $y+z-4 n=x *(z+y-2 n)=x *(z * y)$. 
Example 3. Let

$$
S=\left\{\left(\begin{array}{ll}
x & 0 \\
0 & 0
\end{array}\right): x \text { is a integralnumber }\right\} \cup\left\{\left(\begin{array}{ll}
1 & 0 \\
0 & 1
\end{array}\right),\left(\begin{array}{cc}
1 & 0 \\
0 & -1
\end{array}\right)\right\}
$$

Denote $S_{1}=\left\{\left(\begin{array}{ll}a & 0 \\ 0 & 0\end{array}\right):\right.$ a isaintegralnumber $\}, S_{2}=\left\{\left(\begin{array}{ll}1 & 0 \\ 0 & 1\end{array}\right),\left(\begin{array}{cc}1 & 0 \\ 0 & -1\end{array}\right)\right\}$. Define the operation *on $S: \forall x, y \in S,(1)$ if $x \in S_{1}$ or $y \in S_{1}, x^{*} y$ is common matrix multiplication; (2) if $x \in S_{2}$ and $y \in S_{2}, x^{*} y=\left(\begin{array}{ll}1 & 0 \\ 0 & 1\end{array}\right)$. Then $\left(S,{ }^{*}\right)$ is a TA-groupoid. In fact, we can verify that $\left(x^{*} y\right)^{*} z=x^{*}\left(z^{*} y\right) \forall x, y, z \in S$, since

(i) if $x, y, z \in S_{1}$, by the definition of operation * we can get $\left(x^{*} y\right)^{*} z=x^{*}\left(y^{*} z\right)=x^{*}\left(z^{*} y\right)$;

(ii) if $x, y, z \in S_{2}$, then $\left(x^{*} y\right)^{*} z=\left(\begin{array}{ll}1 & 0 \\ 0 & 1\end{array}\right)=x^{*}\left(z^{*} y\right)$, by (2) in the definition of operation *;

(iii) if $x \in S_{2}, y, z \in S_{1}$, then $\left(x^{*} y\right)^{*} z=y^{*} z=z^{*} y=x^{*}\left(z^{*} y\right)$, by (1) in the definition of operation *;

(iv) if $x \in S_{2}, y \in S_{2}, z \in S_{1}$, then $\left(x^{*} y\right)^{*} z=\left(\begin{array}{ll}1 & 0 \\ 0 & 1\end{array}\right) * z=z=z^{*} y=x^{*}\left(z^{*} y\right)$, by the definition of operation *;

(v) if $x \in S_{2}, y \in S_{1}, z \in S_{2}$, then $\left(x^{*} y\right)^{*} z=y^{*} z=y=z^{*} y=x^{*}\left(z^{*} y\right)$, by the definition of operation ${ }^{*}$;

(vi) if $x \in S_{1}, y \in S_{2}, z \in S_{1}$, then $\left(x^{*} y\right)^{*} z=x^{*} z=x^{*}\left(z^{*} y\right)$, by (1) in the definition of operation *;

(vii) if $x \in S_{1}, y \in S_{1}, z \in S_{2}$, then $\left(x^{*} y\right)^{*} z=x^{*} y=x^{*}\left(z^{*} y\right)$, by (1) in the definition of operation *;

(vii) if $\mathrm{x} \in S_{1}, y \in S_{2}, z \in S_{2}$, then $\left(x^{*} y\right)^{*} z=x^{*} z=x=x^{*}\left(\begin{array}{ll}1 & 0 \\ 0 & 1\end{array}\right)=x^{*}\left(z^{*} y\right)$, by (1) and (2) in the definition of operation *.

Example 4. Table 2 shows the non-commutative TA-groupoid of order 5. Since $\left(b^{*} a\right)^{*} b \neq b *(a * b),(a * b) * b$ $\neq\left(b^{*} b\right)^{*} a$, so $\left(S,{ }^{*}\right)$ is not a semigroup, and it is not an AG-groupoid.

Table 2. Cayley table on $S=\{a, b, c, d, e\}$.

\begin{tabular}{llllll}
\hline$*$ & $\boldsymbol{a}$ & $\boldsymbol{b}$ & $c$ & $\boldsymbol{d}$ & $\boldsymbol{e}$ \\
\hline $\boldsymbol{a}$ & $a$ & $a$ & $a$ & $a$ & $a$ \\
$\boldsymbol{b}$ & $d$ & $d$ & $c$ & $c$ & $b$ \\
$c$ & $d$ & $c$ & $c$ & $c$ & $c$ \\
$\boldsymbol{d}$ & $d$ & $d$ & $c$ & $c$ & $c$ \\
$\boldsymbol{e}$ & $d$ & $c$ & $c$ & $c$ & $e$ \\
\hline
\end{tabular}

From the following example, we know that there exists TA-groupoid which is a non- commutative semigroup, moreover, we can generate some semirings from a TA-groupoid.

Example 5. As shown in Table 3, put $S=\{s, t, u, v, w\}$, and define the operations ${ }^{*}$ on $S$. Then we can verify through MATLAB that $\left(S,{ }^{*}\right)$ is a TA-groupoid, and $\left(S,{ }^{*}\right)$ is a semigroup.

Table 3. Cayley table on $S=\{s, t, u, v, w\}$.

\begin{tabular}{cccccc}
\hline$*$ & $s$ & $\boldsymbol{t}$ & $\boldsymbol{u}$ & $\boldsymbol{v}$ & $\boldsymbol{w}$ \\
\hline $\boldsymbol{s}$ & $s$ & $s$ & $s$ & $s$ & $s$ \\
$\boldsymbol{t}$ & $t$ & $t$ & $t$ & $t$ & $t$ \\
$\boldsymbol{u}$ & $s$ & $s$ & $u$ & $u$ & $s$ \\
$\boldsymbol{v}$ & $s$ & $s$ & $u$ & $v$ & $s$ \\
$\boldsymbol{w}$ & $t$ & $t$ & $w$ & $w$ & $t$ \\
\hline
\end{tabular}


Now, define the operation + on $S$ as Table 4 (or Table 5), then $(\forall m, n, p \in S)(m+n) * p=m * p+n * p$ and $(S ;+, *)$ is a semiring (see [27]).

Table 4. A Commutative semigroup $(S,+)$.

\begin{tabular}{cccccc}
\hline $\boldsymbol{+}$ & $\boldsymbol{s}$ & $\boldsymbol{t}$ & $\boldsymbol{u}$ & $\boldsymbol{v}$ & $\boldsymbol{w}$ \\
\hline $\boldsymbol{s}$ & $s$ & $t$ & $u$ & $u$ & $w$ \\
$\boldsymbol{t}$ & $t$ & $s$ & $w$ & $w$ & $u$ \\
$\boldsymbol{u}$ & $u$ & $w$ & $u$ & $u$ & $w$ \\
$\boldsymbol{v}$ & $u$ & $w$ & $u$ & $u$ & $w$ \\
$\boldsymbol{w}$ & $w$ & $u$ & $w$ & $w$ & $u$ \\
\hline
\end{tabular}

Table 5. Another commutative semigroup $(S,+)$ with unit $s$.

\begin{tabular}{cccccc}
\hline $\boldsymbol{t}$ & $\boldsymbol{s}$ & $\boldsymbol{t}$ & $\boldsymbol{u}$ & $\boldsymbol{v}$ & $\boldsymbol{w}$ \\
\hline $\boldsymbol{s}$ & $s$ & $t$ & $u$ & $v$ & $w$ \\
$\boldsymbol{t}$ & $t$ & $t$ & $w$ & $w$ & $w$ \\
$\boldsymbol{u}$ & $u$ & $w$ & $u$ & $u$ & $w$ \\
$\boldsymbol{v}$ & $v$ & $w$ & $u$ & $u$ & $w$ \\
$\boldsymbol{w}$ & $w$ & $w$ & $w$ & $w$ & $w$ \\
\hline
\end{tabular}

Proposition 4. (1) If $(S, *)$ is a commutative semigroup, then $(S, *)$ is a TA-groupoid. (2) Let $\left(S,{ }^{*}\right)$ be a commutative TA-groupoid. Then $\left(S,{ }^{*}\right)$ is a commutative semigroup.

Proof. It is easy to verify from the definitions.

\section{Various Properties of Tarski Associative Groupoids (TA-Groupoids)}

In this section, we discussed the basic properties of TA-groupoids, gave some typical examples, and established its relationships with CA-AG-groupoids and semigroups (see Figure 2). Furthermore, we discussed the cancellative and direct product properties that are important for exploring the structure of TA-groupoids.

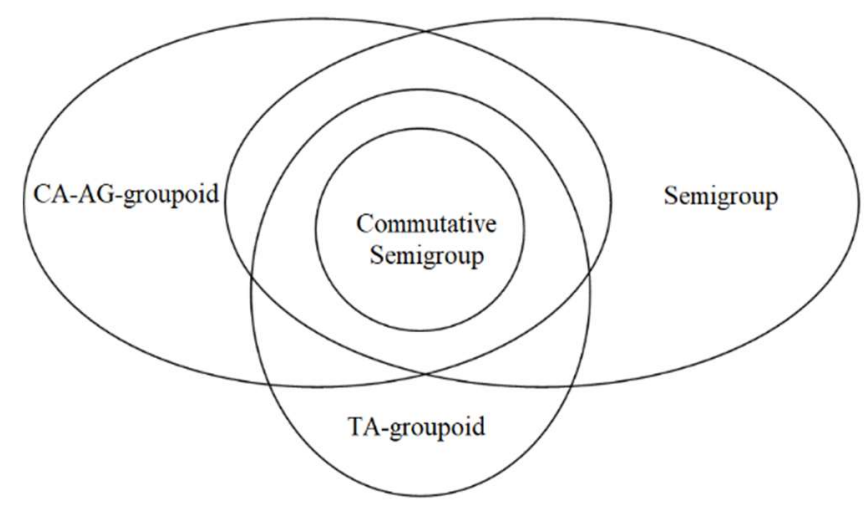

Figure 2. The relationships among some algebraic systems.

Proposition 5. Let $\left(S,{ }^{*}\right)$ be a TA-groupoid. Then $\forall m, n, p, r, s, t \in S$ :

(1) $\left(m^{*} n\right) *\left(p^{*} r\right)=\left(m^{*} r\right)^{*}\left(p^{*} n\right)$;

(2) $\quad\left(\left(m^{*} n\right)^{*}\left(p^{*} r\right)\right)^{*}\left(s^{*} t\right)=\left(m^{*} r\right)^{*}\left(\left(s^{*} t\right)^{*}\left(p^{*} n\right)\right)$. 
Proof. (1) Assume that $\left(S,{ }^{*}\right)$ is a TA-groupoid, then for any $m, n, p, r \in S$, by Definition 6, we have

$$
\left(m^{*} n\right) *\left(p^{*} r\right)=m^{*}\left(\left(p^{*} r\right) * n\right)=m^{*}\left(p^{*}(n * r)\right)=\left(m^{*}(n * r)\right) * p=\left(\left(m^{*} r\right) * n\right) * p=\left(m^{*} r\right) *(p * n) .
$$

(2) For any $m, n, p, r, s, t \in S$, by Definition 6 , we have

$$
\begin{gathered}
\left(\left(m^{*} n\right) *\left(p^{*} r\right)\right) *\left(s^{*} t\right)=\left(m^{*} n\right) *\left(\left(s^{*} t\right) *\left(p^{*} r\right)\right)=\left(m^{*} n\right) *\left(\left(s^{*} r\right) *\left(p^{*} t\right)\right)=\left(\left(m^{*} n\right)^{*}\left(p^{*} t\right)\right) *\left(s^{*} r\right) \\
=\left(\left(m^{*} n\right)^{*} r\right)^{*}\left(s^{*}\left(p^{*} t\right)\right)=\left(\left(m^{*} n\right) * r\right)^{*}\left(\left(s^{*} t\right) *{ }^{*} p\right)=\left(\left(m^{*} n\right) *\right)^{*}\left(\left(s^{*} t\right) * r\right) \\
=\left(m^{*}\left(p^{*} n\right)\right)^{*}\left(\left(s^{*} t\right)^{*} r\right)=\left(m^{*} r\right)^{*}\left(\left(s^{*} t\right)^{*}\left(p^{*} n\right)\right) .
\end{gathered}
$$

Theorem 1. Assume that $\left(S,{ }^{*}\right)$ is a TA-groupoid.

(1) If $\exists e \in S$ such that $(\forall a \in S) e^{*} a=a$, then $\left(S,{ }^{*}\right)$ is a commutative semigroup.

(2) If $e \in S$ is a left identity element in $S$, then e is an identity element in $S$.

(3) If $S$ is a right commutative CA-groupoid, then $S$ is an AG-groupoid.

(4) If $S$ is a right commutative $C A$-groupoid, then $S$ is a left commutative $C A$-groupoid.

(5) If $S$ is a left commutative $C A$-groupoid, then $S$ is a right commutative $C A$-groupoid.

(6) If $S$ is a left commutative CA-groupoid, then $S$ is an AG-groupoid.

(7) If $S$ is a left commutative semigroup, then $S$ is a $C A$-groupoid.

Proof. It is easy to verify from the definitions, and the proof is omitted.

From the following example, we know that a right identity element in $S$ may be not an identity element in $S$.

Example 6. TA-groupoid of order 6 is given in Table 6 , and $e_{6}$ is a right identity element in $S$, but $e_{6}$ is not a left identity element in $S$.

Table 6. Cayley table on $S=\left\{e_{1}, e_{2}, e_{3}, e_{4}, e_{5}, e_{6}\right\}$

\begin{tabular}{lllllll}
\hline$*$ & $\boldsymbol{e}_{\mathbf{1}}$ & $\boldsymbol{e}_{\mathbf{2}}$ & $\boldsymbol{e}_{\mathbf{3}}$ & $\boldsymbol{e}_{\mathbf{4}}$ & $\boldsymbol{e}_{\mathbf{5}}$ & $\boldsymbol{e}_{\mathbf{6}}$ \\
\hline $\boldsymbol{e}_{\mathbf{1}}$ & $e_{1}$ & $e_{1}$ & $e_{1}$ & $e_{1}$ & $e_{1}$ & $e_{1}$ \\
$\boldsymbol{e}_{\mathbf{2}}$ & $e_{2}$ & $e_{2}$ & $e_{2}$ & $e_{2}$ & $e_{2}$ & $e_{2}$ \\
$\boldsymbol{e}_{\mathbf{3}}$ & $e_{1}$ & $e_{1}$ & $e_{4}$ & $e_{6}$ & $e_{1}$ & $e_{3}$ \\
$\boldsymbol{e}_{\mathbf{4}}$ & $e_{1}$ & $e_{1}$ & $e_{6}$ & $e_{3}$ & $e_{1}$ & $e_{4}$ \\
$\boldsymbol{e}_{\mathbf{5}}$ & $e_{2}$ & $e_{2}$ & $e_{5}$ & $e_{5}$ & $e_{2}$ & $e_{5}$ \\
$\boldsymbol{e}_{\mathbf{6}}$ & $e_{1}$ & $e_{1}$ & $e_{3}$ & $e_{4}$ & $e_{1}$ & $e_{6}$ \\
\hline
\end{tabular}

By Theorem 1 (1) and (2) we know that the left identity element in a TA-groupoid is unique. But the following example shows that the right identity element in a TA-groupoid may be not unique.

Example 7. The following non-commutative TA-groupoid of order 5 given in Table 7. Moreover, $x_{1}$ and $x_{2}$ are right identity elements in $S$.

Table 7. Cayley table on $S=\left\{x_{1}, x_{2}, x_{3}, x_{4}, x_{5}\right\}$.

\begin{tabular}{llllll}
\hline$*$ & $x_{1}$ & $x_{2}$ & $x_{3}$ & $x_{4}$ & $x_{5}$ \\
\hline$x_{1}$ & $x_{1}$ & $x_{1}$ & $x_{3}$ & $x_{3}$ & $x_{5}$ \\
$x_{2}$ & $x_{2}$ & $x_{2}$ & $x_{4}$ & $x_{4}$ & $x_{5}$ \\
$x_{3}$ & $x_{3}$ & $x_{3}$ & $x_{1}$ & $x_{1}$ & $x_{5}$ \\
$x_{4}$ & $x_{4}$ & $x_{4}$ & $x_{2}$ & $x_{2}$ & $x_{5}$ \\
$x_{5}$ & $x_{5}$ & $x_{5}$ & $x_{5}$ & $x_{5}$ & $x_{5}$ \\
\hline
\end{tabular}


Theorem 2. Let $\left(S,{ }^{*}\right)$ be a TA-groupoid.

(1) If $S$ is a left commutative AG-groupoid, then $S$ is a CA-groupoid.

(2) If $S$ is a left commutative AG-groupoid, then $S$ is a right commutative TA-groupoid.

(3) If $S$ is a right commutative AG-groupoid, then $S$ is a left commutative TA-groupoid

(4) If $S$ is a right commutative AG-groupoid, then $S$ is a $C A$-groupoid.

(5) If $S$ is a left commutative semigroup, then $S$ is an AG-groupoid.

Proof. It is easy to verify from the definitions, and the proof is omitted.

Theorem 3. Let $\left(S,{ }^{*}\right)$ be a groupoid.

(1) If $S$ is a $C A-A G$-groupoid and a semigroup, then $S$ is a TA-groupoid.

(2) If $S$ is a $C A-A G$-groupoid and a TA-groupoid, then $S$ is a semigroup.

(3) If $S$ is a semigroup, TA-groupoid and CA-groupoid, then $S$ is an AG-groupoid.

(4) If $S$ is a semigroup, TA-groupoid and AG-groupoid, $S$ is a CA-groupoid.

Proof. (1) If $(S, *)$ is a CA-AG-groupoid and a semigroup, then by Definition $2, \forall a, b, c \in S$ :

$$
b *(c * a)=c *(a * b)=(c * a) * b=(b * a) * c .
$$

It follows that $(S, *)$ is a TA-groupoid by Definition 6 .

(2) Assume that $\left(S,{ }^{*}\right)$ is a CA-AG-groupoid and a TA-groupoid, by Definition 2, $\forall a, b, c \in S$ :

$$
a *(b * c)=c *(a * b)=(c * b) * a=(a * b) * c .
$$

This means that $(S, *)$ is a semigroup.

(3) Assume that $\left(S,{ }^{*}\right)$ is a semigroup, TA-groupoid and CA-groupoid. Then, we have $(\forall a, b, c \in S)$ :

$$
(a * b) * c=a *(b * c)=c *(a * b)=(c * b) * a .
$$

Thus, $\left(S,{ }^{*}\right)$ is an AG-groupoid.

(4) Suppose that $\left(S,{ }^{*}\right)$ is a semigroup, TA-groupoid and AG-groupoid. $\forall a, b, c \in S$ :

$$
c^{*}\left(b^{*} a\right)=\left(c^{*} b\right) * a=\left(a^{*} b\right) * c=a *(c * b) .
$$

That is, $(S, *)$ is a CA-groupoid by Definition 3 .

Example 8. Put $S=\{e, f, g, h, i\}$. The operation * is defined on $S$ in Table 8. We can get that $\left(S,{ }^{*}\right)$ is a CA-AG-groupoid. But $\left(S,{ }^{*}\right)$ is not a TA-groupoid, due to the fact that $\left(i^{*} h\right)^{*} i \neq i *(i * h)$. Moreover, $\left(S,{ }^{*}\right)$ is not a semigroup, because $(i * i) * i \neq i *(i * i)$.

Table 8. Cayley table on $S=\{e, f, g, h, i\}$.

\begin{tabular}{cccccc}
\hline$*$ & $\boldsymbol{e}$ & $f$ & $\boldsymbol{g}$ & $\boldsymbol{h}$ & $\boldsymbol{i}$ \\
\hline $\boldsymbol{e}$ & $e$ & $e$ & $e$ & $e$ & $e$ \\
$f$ & $e$ & $e$ & $e$ & $e$ & $e$ \\
$\boldsymbol{g}$ & $e$ & $e$ & $e$ & $e$ & $f$ \\
$\boldsymbol{h}$ & $e$ & $e$ & $e$ & $e$ & $f$ \\
$\boldsymbol{i}$ & $e$ & $e$ & $e$ & $g$ & $h$ \\
\hline
\end{tabular}

From Proposition 4, Theorems 1-3, Examples 4-5 and Example 8, we get the relationships among TA-groupoids and its closely linked algebraic systems, as shown in Figure 2. 
Theorem 4. Let $\left(S,{ }^{*}\right)$ be a TA-groupoid.

(1) Every left cancellative element in $S$ is right cancellative element;

(2) if $x, y \in S$ and they are left cancellative elements, then $x^{*} y$ is a left cancellative element;

(3) if $x$ is left cancellative and $y$ is right cancellative, then $x^{*} y$ is left cancellative;

(4) if $x^{*} y$ is right cancellative, then $y$ is right cancellative;

(5) If for all $a \in S, a^{2}=a$, then it is associative. That is, $S$ is a band.

Proof. (1) Suppose that $x$ is a left cancellative element in $S$. If $(\forall p, q \in S) p^{*} x=q^{*} x$, then:

$$
\begin{gathered}
x^{*}\left(x^{*}\left(x^{*} p\right)\right)=\left(x^{*}\left(x^{*} p\right)\right)^{*} x=\left(\left(x^{*} p\right)^{*} x\right)^{*} x=\left(x^{*} p\right)^{*}\left(x^{*} x\right) \\
=x^{*}\left(\left(x^{*} x\right)^{*} p\right)=x^{*}\left(x^{*}\left(p^{*} x\right)\right)=x^{*}\left(x^{*}\left(q^{*} x\right)\right) \\
=x^{*}\left(\left(x^{*} x\right)^{*} q\right)=\left(x^{*} q\right)^{*}\left(x^{*} x\right)=\left(\left(x^{*} q\right)^{*} x\right)^{*} x \\
=\left(x^{*}\left(x^{*} q\right)\right)^{*} x=x^{*}\left(x^{*}\left(x^{*} q\right)\right) .
\end{gathered}
$$

From this, applying left cancellability, $x^{*}\left(x^{*} p\right)=x^{*}\left(x^{*} q\right)$. From this, applying left cancellability two times, we get that $p=q$. Therefore, $x$ is right cancellative.

(2) If $x$ and $y$ are left cancellative, and $(\forall p, q \in S)\left(x^{*} y\right)^{*} p=\left(x^{*} y\right)^{*} q$, there are:

$$
\begin{gathered}
x^{*}\left(x^{*}\left(y^{*} p\right)\right)=x^{*}\left(\left(x^{*} p\right)^{*} y\right)=\left(x^{*} y\right)^{*}\left(x^{*} p\right) \\
=\left(x^{*} p\right)^{*}\left(x^{*} y\right)(\text { by Proposition } 5(1)) \\
=x\left(\left(x^{*} y\right)^{*} p\right)=x\left((x y)^{*} p\right)=x\left((x y)^{*} q\right)=x\left(\left(x^{*} y\right)^{*} q\right) \\
=\left(x^{*} q\right)^{*}\left(x^{*} y\right)=\left(x^{*} y\right)^{*}\left(x^{*} q\right)=x^{*}\left(\left(x^{*} q\right)^{*} y\right) \\
=x^{*}\left(x^{*}\left(y^{*} q\right)\right) .
\end{gathered}
$$

Applying the left cancellation property of $x$, we have $y^{*} p=y^{*} q$. Moreover, since $y$ is left cancellative, we can get that $p=q$. Therefore, $x^{*} y$ is left cancellative.

(3) Suppose that $x$ is left cancellative and $y$ is right cancellative. If $(\forall p, q \in S)\left(x^{*} y\right)^{*} p=\left(x^{*} y\right)^{*} q$, there are:

$$
x^{*}\left(p^{*} y\right)=\left(x^{*} y\right)^{*} p=\left(x^{*} y\right)^{*} q=x^{*}\left(q^{*} y\right) .
$$

Applying the left cancellation property of $x$, we have $p^{*} y=q^{*} y$. Moreover, since $y$ is right cancellative, we can get that $p=q$. Therefore, $x^{*} y$ is left cancellative.

(4) If $x^{*} y$ is right cancellative, and $p^{*} y=q^{*} y, p, q \in S$, there are:

$$
p^{*}\left(x^{*} y\right)=\left(p^{*} y\right)^{*} x=\left(q^{*} y\right)^{*} x=q^{*}\left(x^{*} y\right) .
$$

Applying the right cancellation property of $x^{*} y$, we have $p=q$. Hence, we get that $y$ is right cancellative.

(5) Assume that for all $a \in S, a^{2}=a$. Then, $\forall r, s, t \in S$,

$$
\begin{aligned}
r^{*}\left(s^{*} t\right) & =\left(r^{*}\left(s^{*} t\right)\right)^{*}\left(r^{*}\left(s^{*} t\right)\right)=r^{*}\left(\left(r^{*}\left(s^{*} t\right)\right)^{*}\left(s^{*} t\right)\right) \\
& =r^{*}\left(r^{*}\left(\left(s^{*} t\right)^{*}\left(s^{*} t\right)\right)\right)=r^{*}\left(r^{*}\left(s^{*} t\right)\right) .
\end{aligned}
$$

Similarly, according to (1) we can get $r^{*}\left(t^{*} s\right)=r^{*}\left(r^{*}\left(t^{*} s\right)\right)$. And, by Proposition 5 (1), we have

$$
\begin{aligned}
r^{*}\left(r^{*}\left(S^{*} t\right)\right) & =r^{*}\left(\left(r^{*} t\right)^{*} S\right)=\left(r^{*} S\right)^{*}\left(r^{*} t\right)=\left(r^{*} t\right)^{*}\left(r^{*} S\right) \\
& =r^{*}\left(\left(r^{*} S\right)^{*} t\right)=r^{*}\left(r^{*}\left(t^{*} S\right)\right) .
\end{aligned}
$$


Combining the results above, we get that $r^{*}\left(s^{*} t\right)=r^{*}\left(r^{*}\left(s^{*} t\right)\right)=r^{*}\left(r^{*}\left(t^{*} s\right)\right)=r^{*}\left(t^{*} s\right)$. Moreover, by Definition $6,\left(r^{*} s\right)^{*} t=r^{*}\left(t^{*} S\right)$. Thus

$$
\left(r^{*} s\right)^{*} t=r^{*}\left(t^{*} s\right)=r^{*}\left(s^{*} t\right)
$$

This means that $S$ is a semigroup, and for all $a \in S, a^{2}=a$.

Therefore, we get that $S$ is a band.

Example 9. TA-groupoid of order 4, given in Table 9. It is easy to verify that $(S, *)$ is a band, due to the fact that $x * x=x, y * y=y, z * z=z, u * u=u$.

Table 9. Cayley table on $S=\{x, y, z, u\}$.

\begin{tabular}{lllll}
\hline$*$ & $\boldsymbol{x}$ & $\boldsymbol{y}$ & $\boldsymbol{z}$ & $\boldsymbol{u}$ \\
\hline $\boldsymbol{x}$ & $x$ & $x$ & $x$ & $x$ \\
$y$ & $y$ & $y$ & $z$ & $y$ \\
$z$ & $u$ & $u$ & $z$ & $u$ \\
$u$ & $u$ & $u$ & $u$ & $u$ \\
\hline
\end{tabular}

Definition 7. Assume that $\left(S_{1},{ }_{1}\right)$ and $\left(S_{2},{ }^{*}\right)$ are TA-groupoids, $S_{1} \times S_{2}=\left\{(a, b) \mid a \in S_{1}, b \in S_{2}\right\}$. Define the operation * on $S_{1} \times S_{2}$ as follows:

$$
\left(a_{1}, a_{2}\right) *\left(b_{1}, b_{2}\right)=\left(a_{1}{ }_{1} b_{1}, a_{2}{ }^{*}{ }_{2} b_{2}\right) \text {, for any }\left(a_{1}, a_{2}\right),\left(b_{1}, b_{2}\right) \in S_{1} \times S_{2} \text {. }
$$

Then $\left(S_{1} \times S_{2}, *\right)$ is called the direct product of $\left(S_{1},{ }^{*}\right)$ and $\left(S_{2},{ }^{*}\right)$.

Theorem 5. If $\left(S_{1},{ }^{*}\right)$ and $\left(S_{2},{ }^{*}\right)$ are TA-groupoids, then their direct product $\left(S_{1} \times S_{2},{ }^{*}\right)$ is a TA-groupoid.

Proof. Assume that $\left(a_{1}, a_{2}\right),\left(b_{1}, b_{2}\right),\left(c_{1}, c_{2}\right) \in S_{1} \times S_{2}$. Since

$$
\begin{aligned}
\left(\left(a_{1}, a_{2}\right) *\left(\left(b_{1}, b_{2}\right)\right) *\left(c_{1}, c_{2}\right)\right. & =\left(a_{1} *_{1} b_{1}, a_{2} *_{2} b_{2}\right) *\left(c_{1}, c_{2}\right) \\
=\left(\left(a_{1}{ }_{1} b_{1}\right)^{*} c_{1},\left(a_{2}{ }_{2} b_{2}\right)_{2} c_{2}\right) & =\left(a_{1} * c_{1}\left(c_{1} * b_{1}\right), a_{2}{ }_{2}\left(c_{2}{ }_{2} b_{2}\right)\right) \\
=\left(a_{1}, a_{2}\right) *\left(c_{1}{ }_{1} b_{1}, c_{2}{ }_{2} b_{2}\right) & =\left(a_{1}, a_{2}\right) *\left(\left(c_{1}, c_{2}\right) *\left(b_{1}, b_{2}\right)\right) .
\end{aligned}
$$

Hence, $\left(S_{1} \times S_{2},{ }^{*}\right)$ is a TA-groupoid.

Theorem 6. Let $\left(S_{1},{ }^{*}\right)$ and $\left(S_{2},{ }^{*}\right)$ be two TA-groupoids, if $x$ and $y$ are cancellative $\left(x \in S_{1}, y \in S_{2}\right)$, then $(x$, y) $\in S_{1} \times S_{2}$ is cancellative.

Proof. Using Theorem 5 , we can get that $S_{1} \times S_{2}$ is a TA-groupoid. Moreover, for any $\left(s_{1}, s_{2}\right),\left(t_{1}, t_{2}\right) \in$ $s_{1} \times S_{2}$, if $(x, y) *\left(s_{1}, s_{2}\right)=(x, y) *\left(t_{1}, t_{2}\right)$, there are:

$$
\begin{gathered}
\left(x s_{1}, y s_{2}\right)=\left(x t_{1}, y t_{2}\right) \\
x s_{1}=x t_{1}, y s_{2}=y t_{2} .
\end{gathered}
$$

Since $x$ and $y$ are cancellative, so $s_{1}=t_{1}, s_{2}=t_{2}$, and $\left(s_{1}, s_{2}\right)=\left(t_{1}, t_{2}\right)$.

Therefore, $(x, y)$ is cancellative.

\section{Tarski Associative Neutrosophic Extended Triplet Groupoids (TA-NET-Groupoids) and Weak Commutative TA-NET-Groupoids (WC-TA-NET-Groupoids)}

In this section, we first propose a new concept of TA-NET-groupoids and discuss its basic properties. Next, this section will discuss an important kind of TA-NET-groupoids, called weak 
commutative TA-NET-groupoids (WC-TA-NET-groupoids). In particular, we proved some well-known properties of WC-TA-NET-groupoids.

Definition 8. Let $\left(S,{ }^{*}\right)$ be a neutrosophic extended triplet set. If

(1) (S, *) is well-defined, that is, $(\forall x, y \in S) x^{*} y \in S$;

(2) $\left(S,{ }^{*}\right)$ is Tarski associative, that is, for any $x, y, z \in S\left(x^{*} y\right)^{*} z=x^{*}\left(z^{*} y\right)$.

Then $(S, *)$ is called a Tarski associative neutrosophic extended triplet groupoid (or TA-NET-groupoid). A TA-NET-groupoid $(S, *)$ is called to be commutative, if $(\forall x, y \in S) x^{*} y=y^{*} x$.

According to the definition of the TA-NET-groupoid, element $a$ may have multiple neutral elements neut $(a)$. We tried using the MATLAB math tools to find an example showing that an element's neutral element is not unique. Unfortunately, we did not find this example. This leads us to consider another possibility: every element in a TA-NET-groupoid has a unique neutral element? Fortunately, we successfully proved that this conjecture is correct.

Theorem 7. Let $(S, *)$ be a TA-NET-groupoid. Then the local unit element neut(a) is unique in $S$.

Proof. For any $a \in S$, if there exists $s, t \in\{$ neut $(a)\}$, then $\exists m, n \in S$ there are:

$$
a^{*} s=s^{*} a=a \text { and } a * m=m^{*} a=s ; a * t=t * a=a \text { and } a * n=n * a=t .
$$

(1) $s=t^{*}$ s. Since

$$
s=a^{*} m=\left(t^{*} a\right) * m=t^{*}\left(m^{*} a\right)=t^{*} s .
$$

(2) $t=t * s$. Since

$$
t=n * a=n *(s * a)=(n * a) * s=t^{*} s .
$$

Hence $s=t$ and $\operatorname{neut}(a)$ is unique for any $a \in S$. $\square$

Remark 1. For element a in TA-NET-groupoid $(S, *)$, although neut(a) is unique, we know from Example 10 that anti(a) may be not unique.

Example 10. TA-NET-groupoid of order 6, given in Table 10. While neut $(\Delta)=\Delta,\{$ anti $(\Delta)\}=\{\Delta, \Gamma, I, \vartheta, K\}$.

Table 10. Cayley table on $S=\{\Delta, \Gamma, I, \vartheta, K, \Lambda\}$.

\begin{tabular}{ccccccc}
\hline$*$ & $\Delta$ & $\Gamma$ & $\boldsymbol{I}$ & $\vartheta$ & $\boldsymbol{K}$ & $\boldsymbol{\Lambda}$ \\
\hline $\boldsymbol{\Delta}$ & $\Delta$ & $\Delta$ & $\Delta$ & $\Delta$ & $\Delta$ & $\Delta$ \\
$\Gamma$ & $\Delta$ & $\Gamma$ & $I$ & $\vartheta$ & $K$ & $\Delta$ \\
$\boldsymbol{I}$ & $\Delta$ & $I$ & $K$ & $\Gamma$ & $\vartheta$ & $\Delta$ \\
$\vartheta$ & $\Delta$ & $\vartheta$ & $\Gamma$ & $K$ & $I$ & $\Delta$ \\
$K$ & $\Delta$ & $K$ & $\vartheta$ & $I$ & $\Gamma$ & $\Delta$ \\
$\Lambda$ & $\Lambda$ & $\Lambda$ & $\Lambda$ & $\Lambda$ & $\Lambda$ & $\Lambda$ \\
\hline
\end{tabular}

Theorem 8. Let $\left(S,{ }^{*}\right)$ be a TA-NET-groupoid. Then $\forall x \in S$ :

(1) $\operatorname{neut}(x){ }^{*} \operatorname{neut}(x)=\operatorname{neut}(x)$;

(2) $\operatorname{neut}(\operatorname{neut}(x))=\operatorname{neut}(x)$;

(3) $\operatorname{anti}(\operatorname{neut}(x)) \in\{\operatorname{anti}(\operatorname{neut}(x))\}, x=\operatorname{anti}(\operatorname{neut}(x)) * x$. 
Proof. (1) For any $x \in S$, according to $x^{*} \operatorname{anti}(x)=\operatorname{anti}(x)^{*} x=\operatorname{neut}(x)$, we have

$$
\operatorname{neut}(x)^{*} \operatorname{neut}(x)=\operatorname{neut}(x)^{*}\left(\left(\operatorname{anti}(x)^{*} x\right)=\left(\operatorname{neut}(x)^{*} x\right)^{*} \operatorname{anti}(x)=x^{*}(\operatorname{anti}(x))=\operatorname{neut}(x) .\right.
$$

(2) $\forall x \in S$, by the definition of neut(neut $(x))$, there are:

$$
\operatorname{neut}(\operatorname{neut}(x))^{*} \text { neut }(x)=\operatorname{neut}(x)^{*} \text { neut }(\text { neut }(x))=\operatorname{neut}(x) .
$$

Thus,

$\operatorname{neut}(\operatorname{neut}(x))^{*} x=\operatorname{neut}(\operatorname{neut}(x))^{*}\left(x^{*}\right.$ neut $\left.(x)\right)=\left(\operatorname{neut}(\operatorname{neut}(x))^{*} \text { neut }(x)\right)^{*} x=\operatorname{neut}(x)^{*} x=x$;

$x^{*}$ neut $($ neut $(x))=\left(x^{*} \text { neut }(x)\right)^{*}$ neut $($ neut $(x))=x^{*}\left(\right.$ neut $(\text { neut }(x))^{*}$ neut $\left.(x)\right)=x^{*}$ neut $(x)=x$.

Moreover, we can get:

$$
\operatorname{anti}(\operatorname{neut}(x))^{*} \text { neut }(x)=\operatorname{neut}(x)^{*} \operatorname{anti}(\operatorname{neut}(x))=\operatorname{neut}(\operatorname{neut}(x)) \text {. }
$$

Then,

$$
\begin{aligned}
& \left(\operatorname{anti}(\operatorname{neut}(x))^{*} \operatorname{anti}(x)\right)^{*} x=\operatorname{anti}(\operatorname{neut}(x))^{*}\left(x^{*} \operatorname{anti}(x)\right)=\operatorname{anti}(\operatorname{neut}(x))^{*} \text { neut }(x)=\operatorname{neut}(\operatorname{neut}(x)) \text {; } \\
& x^{*}\left(\operatorname{anti}(\operatorname{neut}(x))^{*} \operatorname{anti}(x)\right)=\left(x^{*} \operatorname{anti}(x)\right)^{*} \operatorname{anti}(\text { neut }(x))=\operatorname{neut}(x)^{*} \operatorname{anti}(\text { neut }(x))=\operatorname{neut}(\text { neut }(x)) \text {. }
\end{aligned}
$$

Combining the results above, we get

$$
\begin{gathered}
\operatorname{neut}(\operatorname{neut}(x))^{*} x=x^{*} \text { neut }(\operatorname{neut}(x))=x ; \\
\left(\operatorname{anti}(\operatorname{neut}(x))^{*} \operatorname{anti}(x)\right)^{*} x=x^{*}\left(\operatorname{anti}(\operatorname{neut}(x))^{*} \operatorname{anti}(x)\right)=\operatorname{neut}(\operatorname{neut}(x)) .
\end{gathered}
$$

This means that neut $(n e u t(x))$ is a neutral element of $x$ (see Definition 4). Applying Theorem 6, we get that neut $(\operatorname{neut}(x))=\operatorname{neut}(x)$.

(3) For all $x \in S$, using Definition 8 and above (2),

$$
\begin{gathered}
\operatorname{anti}(\operatorname{neut}(x))^{*} x=\operatorname{anti}(\operatorname{neut}(x))^{*}\left(x^{*}(\operatorname{neut}(x))\right)=\left(\operatorname{anti}(\operatorname{neut}(x))^{*} \operatorname{neut}(x)\right)^{*} x \\
=\operatorname{neut}(\operatorname{neut}(x))^{*} x=\operatorname{neut}(x)^{*} x=x .
\end{gathered}
$$

Thus, $\operatorname{anti}(\operatorname{neut}(x))^{*} x=x$.

Example 11. TA-NET-groupoid of order 4, given in Table 11. And neut $(\alpha)=\alpha, \operatorname{neut}(\beta)=\beta, \operatorname{neut}(\delta)=\delta$, $\{\operatorname{anti}(\alpha)\}=\{\alpha, \delta, \varepsilon\}$. While anti $(\alpha)=\delta$, neut $(\operatorname{anti}(\alpha))=\operatorname{neut}(\delta)=\delta \neq \alpha=\operatorname{neut}(\alpha)$.

Table 11. Cayley table on $S=\{\alpha, \beta, \delta, \varepsilon\}$.

\begin{tabular}{lllll}
\hline$*$ & $\alpha$ & $\beta$ & $\delta$ & $\varepsilon$ \\
\hline$\alpha$ & $\alpha$ & $\alpha$ & $\alpha$ & $\alpha$ \\
$\beta$ & $\beta$ & $\beta$ & $\beta$ & $\beta$ \\
$\delta$ & $\alpha$ & $\alpha$ & $\delta$ & $\delta$ \\
$\varepsilon$ & $\alpha$ & $\alpha$ & $\delta$ & $\varepsilon$ \\
\hline
\end{tabular}

Theorem 9. Let $(S, *)$ be a TA-NET-groupoid. Then $\forall x \in S, \forall m, n \in\{\operatorname{anti}(a)\}, \forall$ anti(a) $\in\{$ anti $(a)\}$ :

(1) $m^{*}(\operatorname{neut}(x))=\operatorname{neut}(x)^{*} n$;

(2) $\operatorname{anti}(\text { neut }(x))^{*} \operatorname{anti}(x) \in\{\operatorname{anti}(x)\}$;

(3) $\operatorname{neut}(x)^{*} \operatorname{anti}(n)=x^{*}$ neut $(n)$;

(4) $\operatorname{neut}(m)^{*}$ neut $(x)=\operatorname{neut}(x)^{*}$ neut $(m)=\operatorname{neut}(x)$; 
(5) $\quad\left(n^{*}(\operatorname{neut}(x))^{*} x=x^{*}\left(\operatorname{neut}(x)^{*} n\right)=\operatorname{neut}(x)\right.$;

(6) $\operatorname{neut}(n)^{*} x=x$.

Proof. (1) By the definition of neutral and opposite element (see Definition 4), applying Theorem 6, there are:

(2) By Theorem 7(2), there are:

$$
\begin{aligned}
m^{*} x=x^{*} m & =\operatorname{neut}(x), n^{*} x=x^{*} n=\operatorname{neut}(x) . \\
m^{*}(\operatorname{neut}(x)) & =m^{*}\left(n^{*} x\right)=\left(m^{*} x\right)^{*} n=\operatorname{neut}(x)^{*} n . \\
x^{*}\left[\operatorname{anti}(\operatorname{neut}(x))^{*} \operatorname{anti}(x)\right] & =\left[x^{*}(\operatorname{anti}(x))\right]^{*} \operatorname{anti}(\operatorname{neut}(x))=\operatorname{neut}(x)^{*} \operatorname{anti}(\operatorname{neut}(x)) \\
& =\operatorname{neut}(\operatorname{neut}(x))=\operatorname{neut}(x) . \\
{\left[\operatorname{anti}(\operatorname{neut}(x))^{*} \operatorname{anti}(x)\right]^{*} x } & =\operatorname{anti}(\operatorname{neut}(x))^{*}\left[x^{*}(\operatorname{anti}(x)]=\operatorname{anti}(\operatorname{neut}(x))^{*} \text { neut }(x)\right. \\
& =\operatorname{neut}(\operatorname{neut}(x))=\operatorname{neut}(x) .
\end{aligned}
$$

Thus, anti(neut $(\mathrm{x}))^{*} \operatorname{anti}(\mathrm{x}) \in\{\operatorname{anti}(\mathrm{x})\}$.

(3) For any $x \in S, n \in\{\operatorname{anti}(a)\}$, by $x^{*} n=n^{*} x=\operatorname{neut}(x)$ and $n^{*} \operatorname{anti}(n)=\operatorname{anti}(n)^{*} n=n e u t(n)$, we get

$$
x^{*} \operatorname{neut}(n)=x^{*}\left[\operatorname{anti}(n)^{*} n\right]=\left(x^{*} n\right)^{*} \operatorname{anti}(n)=\operatorname{neut}(x)^{*} \operatorname{anti}(n) .
$$

This shows that neut $(x)^{*} \operatorname{anti}(n)=x^{*}$ neut $(n)$.

(4) For any $x \in S, m \in\{\operatorname{anti}(x)\}$, by $x^{*} m=m^{*} x=\operatorname{neut}(x)$ and $\operatorname{anti}(m)^{*} m=m^{*} \operatorname{anti}(m)=$ neut $(m)$, there are:

$$
\begin{gathered}
\operatorname{neut}(m)^{*} \operatorname{neut}(x)=\operatorname{neut}(m)^{*}\left(x^{*} m\right)=\left(\operatorname{neut}(m)^{*} m\right)^{*} x=m^{*} x=\operatorname{neut}(x) . \\
\operatorname{neut}(x)^{*} \operatorname{neut}(m)=\operatorname{neut}(x)^{*}\left[m^{*}(\operatorname{anti}(m))\right]=\left[\operatorname{neut}(x)^{*} \operatorname{anti}(m)\right]^{*} m .
\end{gathered}
$$

Applying (3), there are:

$$
\operatorname{neut}(x)^{*} \operatorname{neut}(m)=\left[\operatorname{neut}(x)^{*} \operatorname{anti}(m)\right]^{*} m=\left[x^{*}(\operatorname{neut}(m))\right]^{*} m=x^{*}\left(m^{*}(\operatorname{neut}(m))=x^{*} m=\operatorname{neut}(x)\right. \text {. }
$$

That is,

$$
\operatorname{neut}(m)^{*} \operatorname{neut}(x)=\operatorname{neut}(x)^{*} \operatorname{neut}(m)=\operatorname{neut}(x) .
$$

(5) By $x^{*} n=n^{*} x=\operatorname{neut}(x)$, there are:

$$
\begin{gathered}
{\left[n^{*}(\operatorname{neut}(x))\right]^{*} x=n^{*}\left(x^{*}(\operatorname{neut}(x))\right)=n^{*} x=\operatorname{neut}(x) .} \\
x^{*}\left[\operatorname{neut}(x)^{*} n\right]=\left(x^{*} n\right)^{*}(\operatorname{neut}(x))=\operatorname{neut}(x)^{*} \text { neut }(x)=\operatorname{neut}(x) .
\end{gathered}
$$

Thus, $\left[n^{*}(\operatorname{neut}(x))\right]^{*} x=x^{*}\left[\operatorname{neut}(x)^{*} n\right]=\operatorname{neut}(x)$.

(6) For any $x \in S, n \in\{a n t i(x)\}$, by $x^{*} n=n^{*} x=\operatorname{neut}(x)$,

$$
\operatorname{neut}(n)^{*} x=\operatorname{neut}(n)^{*}\left[x^{*}(\operatorname{neut}(x))\right]=\left[\operatorname{neut}(n)^{*} \operatorname{neut}(x)\right]^{*} x .
$$

From this, applying (4), there are:

$$
\operatorname{neut}(n)^{*} x=\left[\operatorname{neut}(n)^{*} n e u t(x)\right]^{*} x=\operatorname{neut}(x)^{*} x=x .
$$

Hence, $\operatorname{neut}(n)^{*} x=x$.

Proposition 6. Let (S, *) be a TA-NET-groupoid. Then $\forall x, y, z \in S$ :

(1) $y^{*} x=z^{*} x$, implies neut $(x)^{*} y=\operatorname{neut}(x)^{*} z$;

(2) $y^{*} x=z^{*} x$, if and only if $y^{*} n e u t(x)=z^{*}$ neut $(x)$. 
Proof. (1) For any $x, y \in S$, if $y^{*} x=z^{*} x$, then $\operatorname{anti}(x)^{*}\left(y^{*} x\right)=\operatorname{anti}(x)^{*}\left(z^{*} x\right)$. By Definition 6 and Definition 8 there are:

$$
\begin{aligned}
\operatorname{anti}(x)^{*}\left(y^{*} x\right) & =\left(\operatorname{anti}(x)^{*} x\right)^{*} y=\operatorname{neut}(x)^{*} y ; \\
\operatorname{anti}(x)^{*}\left(z^{*} x\right) & =\left(\operatorname{anti}(x)^{*} x\right)^{*} z=\operatorname{neut}(x)^{*} z .
\end{aligned}
$$

Thus neut $(x)^{*} y=\operatorname{anti}(x)^{*}\left(y^{*} x\right)=\operatorname{anti}(x)^{*}\left(z^{*} x\right)=\operatorname{neut}(x)^{*} z$.

(2) For any $x, y \in S$, if $y^{*} x=z^{*} x$, then $\left(y^{*} x\right)^{*} \operatorname{anti}(x)=\left(z^{*} x\right)^{*} \operatorname{anti}(x)$. Since

$$
\left(y^{*} x\right)^{*} \operatorname{anti}(x)=y^{*}\left(\operatorname{anti}(x)^{*} x\right)=y^{*} \text { neut }(x) ;\left(z^{*} x\right)^{*} \operatorname{anti}(x)=z^{*}\left(\operatorname{anti}(x)^{*} x\right)=z^{*} \text { neut }(x) .
$$

It follows that $y^{*}$ neut $(x)=z^{*}$ neut $(x)$. This means that $y^{*} x=z^{*} x$ implies $y^{*}$ neut $(x)=z^{*}$ neut $(x)$.

Conversely, if $y^{*}$ neut $(x)=z^{*}$ neut $(x)$, then $\left(y^{*} \text { neut }(x)\right)^{*} x=\left(z^{*} \text { neut }(x)\right)^{*} x$. Since

$$
\left(y^{*} \text { neut }(x)\right)^{*} x=y^{*}\left(x^{*} \text { neut }(x)\right)=y^{*} x ;\left(z^{*} \text { neut }(x)\right)^{*} x=z^{*}\left(x^{*} \text { neut }(x)\right)=z^{*} x .
$$

Thus, $y^{*} x=z^{*} x$. Hence, $y^{*}$ neut $(x)=z^{*}$ neut $(x)$ implies $y^{*} x=z^{*} x$.

Proposition 7. Suppose that $\left(S,{ }^{*}\right)$ is a commutative TA-NET-groupoid. $\forall x, y \in S$ :

(1) $\operatorname{neut}(x) * \operatorname{neut}(y)=\operatorname{neut}(x * y)$;

(2) $\operatorname{anti}(x) * \operatorname{anti}(y) \in\{\operatorname{anti}(x * y)\}$.

Proof. (1) For any $x, y \in S$, since $S$ is commutative, so $x^{*} y=y^{*} x$. From this, by Proposition 5(1), we have

$\left(x^{*} y\right)^{*}\left(\operatorname{neut}(x)^{*}\right.$ neut $\left.(y)\right)=\left(y^{*} x\right)^{*}\left(\operatorname{neut}(x)^{*}\right.$ neut $\left.(y)\right)=\left(y^{*} \text { neut }(y)\right)^{*}\left(\operatorname{neut}(x)^{*} x\right)=y^{*} x=x^{*} y$; $\left(\operatorname{neut}(x)^{*} \text { neut }(y)\right)^{*}\left(x^{*} y\right)=\left(\operatorname{neut}(x)^{*} \text { neut }(y)\right)^{*}\left(y^{*} x\right)=\left(\operatorname{neut}(x)^{*} x\right)^{*}\left(y^{*}(\right.$ neut $(y))=x^{*} y$.

Moreover, using Proposition 5(1),

$$
\begin{aligned}
\left(\operatorname{anti}(x)^{*} \operatorname{anti}(y)\right)^{*}\left(x^{*} y\right) & =\left(\operatorname{anti}(x)^{*} \operatorname{anti}(y)\right)^{*}\left(y^{*} x\right)=\left(\operatorname{anti}(x)^{*} x\right)^{*}\left(y^{*} \operatorname{anti}(y)\right)=\operatorname{neut}(x)^{*} \text { neut }(y) \\
\left(x^{*} y\right)^{*}\left(\operatorname{anti}(x)^{*} \operatorname{anti}(y)\right) & =\left(x^{*} y\right)^{*}\left(\operatorname{anti}(y)^{*} \operatorname{anti}(x)\right)=\left(x^{*} \operatorname{anti}(x)\right)^{*}\left(\operatorname{anti}(y)^{*} y\right)=\operatorname{neut}(x)^{*} \text { neut }(y) .
\end{aligned}
$$

This means that neut $(x)^{*} n e u t(y)$ is a neutral element of $x^{*} y$ (see Definition 4). Applying Theorem 6, we get that neut $(x)^{*}$ neut $(y)=\operatorname{neut}\left(x^{*} y\right)$.

(2) For any $\operatorname{anti}(x) \in\{\operatorname{anti}(x)\}$, anti $(y) \in\{\operatorname{anti}(y)\}$, by the proof of (1) above,

$$
\left(\operatorname{anti}(x)^{*} \operatorname{anti}(y)\right)^{*}\left(x^{*} y\right)=\left(x^{*} y\right)^{*}\left(\operatorname{anti}(x)^{*} \operatorname{anti}(y)\right)=\operatorname{neut}(x)^{*} \text { neut }(y) \text {. }
$$

From this and applying (1), there are:

$$
\left(\operatorname{anti}(x)^{*} \operatorname{anti}(y)\right)^{*}\left(x^{*} y\right)=\left(x^{*} y\right)^{*}\left(\operatorname{anti}(x)^{*} \operatorname{anti}(y)\right)=\operatorname{neut}\left(x^{*} y\right) .
$$

Hence, $\operatorname{anti}(x)^{*} \operatorname{anti}(y) \in\left\{\operatorname{anti}\left(x^{*} y\right)\right\}$.

Definition 9. Let $(S, *)$ be a TA-NET-groupoid. If $(\forall x, y \in S) x *$ neut $(y)=$ neut $(y) * x$, then we said that $S$ is a weak commutative TA-NET-groupoid (or WC-TA-NET-groupoid).

Proposition 8. Let $\left(S,{ }^{*}\right)$ be a TA-NET-groupoid. Then $\left(S,{ }^{*}\right)$ is weak commutative $\Leftrightarrow S$ satisfies the following conditions $(\forall x, y \in S)$ :

(1) neut $(x)^{*}$ neut $(y)=\operatorname{neut}(y)^{*}$ neut $(x)$.

(2) $\operatorname{neut}(x)^{*}\left(\operatorname{neut}(y)^{*} x\right)=\operatorname{neut}(x)^{*}\left(x^{*}\right.$ neut $\left.(y)\right)$. 
Proof. Assume that $\left(S,{ }^{*}\right)$ is a weak commutative TA-NET-groupoid, using Definition 9 , there are $(\forall x, y \in S)$ :

$$
\begin{aligned}
\operatorname{neut}(x)^{*} \text { neut }(y) & =\operatorname{neut}(y)^{*} \text { neut }(x), \\
\operatorname{neut}(x)^{*}\left(\operatorname{neut}(y)^{*} x\right) & =\operatorname{neut}(x)^{*}\left(x^{*} \text { neut }(y)\right) .
\end{aligned}
$$

In contrast, suppose that $S$ satisfies the above conditions (1) and (2). there $\operatorname{are}(\forall x, y \in S)$ :

$$
\begin{aligned}
& x^{*} \text { neut }(y)=\left(\operatorname{neut}(x)^{*} x\right)^{*} \text { neut }(y)=\operatorname{neut}(x)^{*}\left(\operatorname{neut}(y)^{*} x\right)=\operatorname{neut}(x)^{*}\left(x^{*} \text { neut }(y)\right)= \\
& \left(\operatorname{neut}(x)^{*} \text { neut }(y)\right)^{*} x=\left(\operatorname{neut}(y)^{*} \text { neut }(x)\right)^{*} x=\operatorname{neut}(y)^{*}\left(x^{*} \text { neut }(x)\right)=\operatorname{neut}(y)^{*} x .
\end{aligned}
$$

From Definition 9 and this we can get that $(S, *)$ is a weak commutative TA-NET-groupoid.

Theorem 10. Assume that $\left(S,{ }^{*}\right)$ is a weak commutative TA-NET-groupoid. Then $\forall x, y \in S$ :

(1) neut $(x)^{*}$ neut $(y)=\operatorname{neut}\left(y^{*} x\right)$;

(2) $\operatorname{anti}(x)^{*} \operatorname{anti}(y) \in\left\{\operatorname{anti}\left(y^{*} x\right)\right\}$;

(3) (S is commutative) $\Leftrightarrow$ ( $S$ is weak commutative).

Proof. (1) By Proposition 5 (1)), there are:

$$
\begin{gathered}
{\left[\operatorname{neut}(x)^{*} \text { neut }(y)\right]^{*}\left(y^{*} x\right)=\left[\operatorname{neut}(x)^{*} x\right]^{*}\left[y^{*} \text { neut }(y)\right]=\left[\operatorname{neut}(x)^{*} x\right]^{*}\left[\operatorname{neut}(y)^{*} y\right]=} \\
{\left[\operatorname{neut}(x)^{*} y\right]^{*}\left[\operatorname{neut}(y)^{*} x\right]=\left[y^{*} \operatorname{neut}(x)\right]^{*}\left[x^{*} \text { neut }(y)\right]=\left[y^{*} \operatorname{neut}(y)\right]^{*}\left[x^{*} \operatorname{neut}(x)\right]=y^{*} x .}
\end{gathered}
$$

And, $\left(y^{*} x\right)^{*}\left[\operatorname{neut}(x)^{*} \operatorname{neut}(y)\right]=\left[y^{*} \text { neut }(y)\right]^{*}\left[\operatorname{neut}(x)^{*} x\right]=y^{*} x$. That is,

$$
\left[\operatorname{neut}(x)^{*} \operatorname{neut}(y)\right]^{*}\left(y^{*} x\right)=\left(y^{*} x\right)^{*}\left[\operatorname{neut}(x)^{*} \text { neut }(y)\right]=y^{*} x .
$$

And that, there are:

$$
\begin{gathered}
{\left[\operatorname{anti}(x)^{*} \operatorname{anti}(y)\right]^{*}\left(y^{*} x\right)=\left[\operatorname{anti}(x)^{*} x\right]^{*}\left[y^{*} \operatorname{anti}(y)\right]=\operatorname{neut}(x)^{*} \text { neut }(y) ;} \\
\left(y^{*} x\right)^{*}\left[\operatorname{anti}(x)^{*} \operatorname{anti}(y)\right]=\left[y^{*} \operatorname{anti}(y)\right]^{*}\left[\operatorname{anti}(x)^{*} x\right]=\operatorname{neut}(y)^{*} \text { neut }(x)=\operatorname{neut}(x)^{*} \text { neut }(y) .
\end{gathered}
$$

That is,

$$
\left[\operatorname{anti}(x)^{*} \operatorname{anti}(y)\right]^{*}\left(y^{*} x\right)=\left(y^{*} x\right)^{*}\left[\operatorname{anti}(x)^{*} \operatorname{anti}(y)\right]=\operatorname{neut}(x)^{*} \text { neut }(y) \text {. }
$$

Thus, combining the results above, we know that neut $(x)^{*}$ neut $(y)$ is a neutral element of $y^{*} x$. Applying Theorem 6, we get neut $(x)^{*}$ neut $(y)=$ neut $\left(y^{*} x\right)$.

(2) Using (1) and the following result (see the proof of (1))

$$
\left[\operatorname{anti}(x)^{*} \operatorname{anti}(y)\right]^{*}\left(y^{*} x\right)=\left(y^{*} x\right)^{*}\left[\operatorname{anti}(x)^{*} \operatorname{anti}(y)\right]=\operatorname{neut}(x)^{*} \text { neut }(y)
$$

we can get that $\operatorname{anti}(x)^{*} \operatorname{anti}(y) \in\left\{\operatorname{anti}\left(y^{*} x\right)\right\}$.

(3) If $S$ is commutative, then $S$ is weak commutative.

On the other hand, suppose that $S$ is a TA-NET-groupoid and $S$ is weak commutative. By Proposition 5 (1) and Definition 9, there are:

$$
\begin{gathered}
x^{*} y=\left(x^{*} \text { neut }(x)\right)^{*}\left(y^{*} \text { neut }(y)\right)=\left(x^{*} \text { neut }(y)\right)^{*}\left(y^{*} \text { neut }(x)\right)=\left(\operatorname{neut}(y)^{*} x\right)^{*}\left(\operatorname{neut}(x)^{*} y\right) \\
=\left(\operatorname{neut}(y)^{*} y\right)^{*}\left(\operatorname{neut}(x)^{*} x\right)=y^{*} x .
\end{gathered}
$$

Therefore, $S$ is a commutative TA-NET-groupoid. 


\section{Decomposition Theorem of TA-NET-Groupoids}

This section generalizes the well-known Clifford's theorem in semigroup to TA-NET-groupoid, which is very exciting.

Theorem 11. Let $\left(S,{ }^{*}\right)$ be a TA-NET-groupoid. Then for any $x \in S$, and all $m \in\{$ anti(a)\}:

(1) $\operatorname{neut}(x)^{*} m \in\{\operatorname{anti}(x)\}$;

(2) $m^{*} \operatorname{neut}(x)=\left(\operatorname{neut}(x)^{*} m\right)^{*}$ neut $(x)$;

(3) $\operatorname{neut}(x)^{*} m=\left(\operatorname{neut}(x)^{*} m\right)^{*}$ neut $(x)$;

(4) $m^{*}$ neut $(x)=\operatorname{neut}(x)^{*} m$;

(5) $\operatorname{neut}\left(m^{*}(\operatorname{neut}(x))\right)=\operatorname{neut}(x)$.

Proof. (1) For any $x \in S, m \in\{\operatorname{anti}(x)\}$, we have $m^{*} x=x^{*} m=n e u t(x)$. Then, by Definition 6, Theorem 7 (1) and Proposition 5 (1), there are:

$$
\begin{gathered}
x^{*}\left[\operatorname{neut}(x)^{*} m\right]=\left(x^{*} m\right)^{*} \text { neut }(x)=\operatorname{neut}(x)^{*} \text { neut }(x)=\operatorname{neut}(x) ; \\
{\left[\operatorname{neut}(x)^{*} m\right]^{*} x=\left[\operatorname{neut}(x)^{*} m\right]^{*}\left[x^{*} \operatorname{neut}(x)\right]=\left[\operatorname{neut}(x)^{*} \operatorname{neut}(x)\right]^{*}\left(x^{*} m\right)=\left[\operatorname{neut}(x)^{*} \operatorname{neut}(x)\right]^{*} \operatorname{neut}(x)=\operatorname{neut}(x) .}
\end{gathered}
$$

This means that neut $(x)^{*} m \in\{a n t i(x)\}$.

(2) If $x \in S, m \in\{\operatorname{anti}(x)\}$, then $m^{*} x=x^{*} m=n e u t(x)$. Applying (1) and Theorem 8 (1),

$$
m^{*} \operatorname{neut}(x)=\operatorname{neut}(x)^{*}\left[\operatorname{neut}(x)^{*} m\right] \text {. }
$$

On the other hand, using Theorem 7 (1) and Proposition 5 (1), there are:

$\operatorname{neut}(x)^{*}\left[\operatorname{neut}(x)^{*} m\right]=\left(\operatorname{neut}(x)^{*} \operatorname{neut}(x)\right)^{*}\left[\operatorname{neut}(x)^{*} m\right]=\left[\operatorname{neut}(x)^{*} m\right]^{*}\left[\operatorname{neut}(x)^{*} \operatorname{neut}(x)\right]=\left[\operatorname{neut}(x)^{*} m\right]^{*} \operatorname{neut}(x)$.

Combining two equations above, we get $m^{*}$ neut $(x)=\left(\text { neut }(x)^{*} m\right)^{*}$ neut $(x)$.

(3) Assume that $m \in\{\operatorname{anti}(x)\}$, then $x^{*} m=m^{*} x=\operatorname{neut}(x)$ and $m^{*}$ neut $(m)=\operatorname{neut}(m)^{*} m=m$. By Theorem 7 (1), Proposition 5 (1) and Theorem 8 (4), there are:

$\operatorname{neut}(x)^{*} m=\left[\operatorname{neut}(x)^{*} \operatorname{neut}(x)\right]^{*}\left(\operatorname{neut}(m)^{*} m\right)=\left(\operatorname{neut}(x)^{*} m\right)\left[\operatorname{neut}(m)^{*}\right.$ neut $\left.(x)\right]=\left(\operatorname{neut}(x)^{*} m\right)^{*}$ neut $(x)$.

That is, $\operatorname{neut}(x)^{*} m=\left(\operatorname{neut}(x)^{*} m\right)^{*}$ neut $(x)$.

(4) It follows from (2) and (3).

(5) Assume $m \in\{\operatorname{anti}(x)\}$, then $x^{*} m=m^{*} x=\operatorname{neut}(x)$. Denote $t=m^{*}$ neut $(x)$. We prove the following equations,

$$
t^{*} \operatorname{neut}(x)=\operatorname{neut}(x)^{*} t=t ; t^{*} x=x^{*} t=\operatorname{neut}(x) .
$$

By (3) and (4), there are:

$$
t^{*} \text { neut }(x)=\left(m^{*} \text { neut }(x)\right)^{*} \text { neut }(x)=\left(\operatorname{neut}(x)^{*} m\right)^{*} \text { neut }(x)=\operatorname{neut}(x)^{*} m=m^{*} \text { neut }(x)=t .
$$

Using Definition 6, Theorem 7 (1) and Theorem 8 (1), there are:

$$
\operatorname{neut}(x)^{*} t=\operatorname{neut}(x)^{*}\left[m^{*}(\operatorname{neut}(x))\right]=\left(\operatorname{neut}(x)^{*} \text { neut }(x)\right)^{*} m=\operatorname{neut}(x)^{*} m=m^{*} \text { neut }(x)=t .
$$


Moreover, applying Proposition 5 (1), Theorem 7 (1) and Definition 6, there are:

$$
\begin{gathered}
t^{*} x=\left[m^{*}(\operatorname{neut}(x))\right]^{*} x=\left[m^{*} \operatorname{neut}(x)\right]^{*}\left(\operatorname{neut}(x)^{*} x\right)=\left(m^{*} x\right)^{*}\left[\operatorname{neut}(x)^{*} \operatorname{neut}(x)\right] \\
=\operatorname{neut}(x)^{*}\left[\operatorname{neut}(x)^{*} \operatorname{neut}(x)\right]=\operatorname{neut}(x) . \\
x^{*} t=x^{*}\left[m^{*}(\operatorname{neut}(x))\right]=\left[x^{*} \operatorname{neut}(x)\right]^{*} m=x^{*} m=\operatorname{neut}(x) .
\end{gathered}
$$

Thus,

$$
t^{*} n e u t(x)=\operatorname{neut}(x)^{*} t=t ; t^{*} x=x^{*} t=\operatorname{neut}(x) .
$$

By the definition of neutral element and Theorem 6, we get that neut $(x)$ is the neutral element of $t$ $=m^{*}$ neut $(x)$. This means that neut $\left(m^{*}(\right.$ neut $\left.(x))\right)=\operatorname{neut}(x)$.

Theorem 12. Let $(S, *)$ be a TA-NET-groupoid. Then the product of idempotents is still idempotent. That is for any $y_{1}, y_{2} \in S,\left(y_{1} * y_{2}\right) *\left(y_{1} * y_{2}\right)=y_{1} * y_{2}$.

Proof. Assume that $y_{1}, y_{2} \in S$ and $\left(y_{1}{ }^{*} y_{1}=y_{1}, y_{2}{ }^{*} y_{2}=y_{2}\right)$, then:

$$
\left(y_{1}^{*} y_{2}\right)^{*}\left(y_{1}^{*} y_{2}\right)=y_{1}^{*}\left[\left(y_{1}^{*} y_{2}\right)^{*} y_{2}\right]=y_{1}^{*}\left[y_{1}^{*}\left(y_{2}^{*} y_{2}\right)\right]=y_{1}^{*}\left(y_{1}^{*} y_{2}\right) .
$$

From this, applying Definition 4 and Definition 6,

$$
\begin{gathered}
y_{1}^{*} y_{2}=\left[\operatorname{neut}\left(y_{1}^{*} y_{2}\right)\right]^{*}\left(y_{1}^{*} y_{2}\right)=\left[\operatorname{anti}\left(y_{1}^{*} y_{2}\right)^{*}\left(y_{1}^{*} y_{2}\right)\right]^{*}\left(y_{1}^{*} y_{2}\right)=\operatorname{anti}\left(y_{1}^{*} y_{2}\right)^{*}\left[\left(y_{1}^{*} y_{2}\right)^{*}\left(y_{1}^{*} y_{2}\right)\right] \\
=\operatorname{anti}\left(y_{1}^{*} y_{2}\right)^{*}\left[y_{1}^{*}\left(y_{1}^{*} y_{2}\right)\right]\left(\operatorname{By}\left(y_{1}^{*} y_{2}\right)^{*}\left(y_{1}^{*} y_{2}\right)=y_{1}^{*}\left(y_{1}^{*} y_{2}\right)\right) \\
=\left[\operatorname{anti}\left(y_{1}^{*} y_{2}\right)^{*}\left(y_{1}^{*} y_{2}\right)\right]^{*} y_{1}=\operatorname{neut}\left(y_{1}^{*} y_{2}\right)^{*} y_{1} .
\end{gathered}
$$

Thus,

$$
\begin{gathered}
\left(y_{1}^{*} y_{2}\right)^{*}\left(y_{1}^{*} y_{2}\right)=y_{1}^{*}\left(y_{1}^{*} y_{2}\right)=\left(y_{1}^{*} y_{2}\right)^{*} y_{1} \\
=\left[\operatorname{neut}\left(y_{1}{ }^{*} y_{2}\right)^{*} y_{1}\right]^{*} y_{1}\left(\operatorname{By~} y_{1}{ }^{*} y_{2}=\left[\operatorname{neut}\left(y_{1} y_{2}\right)\right]^{*} y_{1}\right) \\
=\operatorname{neut}\left(y_{1}^{*} y_{2}\right)^{*}\left(y_{1}{ }^{*} y_{1}\right)=\operatorname{neut}\left(y_{1}^{*} y_{2}\right)^{*} y_{1}=y_{1}{ }^{*} y_{2} .
\end{gathered}
$$

This means that the product of idempotents is still idempotent.

Example 12. TA-NET-groupoid of order 4, given in Table 12, and the product of any two idempotent elements is still idempotent, due to the fact that,

$$
\begin{array}{r}
\left(z_{1}^{*} z_{2}\right)^{*}\left(z_{1}^{*} z_{2}\right)=z_{1}^{*} z_{2},\left(z_{1}^{*} z_{3}\right)^{*}\left(z_{1}^{*} z_{3}\right)=z_{1}^{*} z_{3},\left(z_{1}^{*} z_{4}\right)^{*}\left(z_{1}^{*} z_{4}\right)=z_{1}^{*} z_{4}, \\
\left(z_{2}^{*} z_{3}\right)^{*}\left(z_{2}{ }^{*} z_{3}\right)=z_{2}{ }^{*} z_{3},\left(z_{2}{ }^{*} z_{4}\right)^{*}\left(z_{2}{ }^{*} z_{4}\right)=z_{2}{ }^{*} z_{4},\left(z_{3}^{*} z_{4}\right)^{*}\left(z_{3}^{*} z_{4}\right)=z_{3}^{*} z_{4} .
\end{array}
$$

Table 12. Cayley table on $S=\left\{z_{1}, z_{2}, z_{3}, z_{4}\right\}$.

\begin{tabular}{lllll}
\hline$*$ & $z_{1}$ & $z_{2}$ & $z_{3}$ & $z_{4}$ \\
\hline$z_{1}$ & $z_{1}$ & $z_{1}$ & $z_{1}$ & $z_{4}$ \\
$z_{2}$ & $z_{2}$ & $z_{2}$ & $z_{2}$ & $z_{4}$ \\
$z_{3}$ & $z_{1}$ & $z_{1}$ & $z_{3}$ & $z_{4}$ \\
$z_{4}$ & $z_{4}$ & $z_{4}$ & $z_{4}$ & $z_{4}$ \\
\hline
\end{tabular}

Theorem 13. Let $\left(S,{ }^{*}\right)$ be a TA-NET-groupoid. Denote $E(S)$ be the set of all different neutral element in $S$, $S(e)=\{a \in S \mid \operatorname{neut}(a)=e\}(\forall e \in E(S))$. Then:

(1) $S(e)$ is a subgroup of $S$.

(2) for any $\mathrm{e}_{1}, \mathrm{e}_{2} \in \mathrm{E}(\mathrm{S}), \mathrm{e}_{1} \neq \mathrm{e}_{2} \Rightarrow \mathrm{S}\left(\mathrm{e}_{1}\right) \cap \mathrm{S}\left(\mathrm{e}_{2}\right)=\emptyset$.

(3) $S=\cup_{e \in E(S)} S(e)$. 
Proof. (1) For any $m \in S(e)$, neut $(m)=e$. That is, $e$ is an identity element in $S(e)$. And, using Theorem 7 (1), we get $e^{*} e=e$.

Assume that $m, n \in S(e)$, then neut $(m)=$ neut $(n)=e$. We're going to prove that neut $\left(m^{*} n\right)=e$.

Applying Definition 6, Proposition 5 (1),

$$
\begin{gathered}
\left(m^{*} n\right)^{*} e=m^{*}\left(e^{*} n\right)=m^{*} n ; \\
e^{*}\left(m^{*} n\right)=\left(e^{*} e\right)^{*}\left(m^{*} n\right)=\left(e^{*} n\right)^{*}\left(m^{*} e\right)=\left(e^{*} n\right)^{*} m \\
=\left(e^{*} n\right)^{*}\left(e^{*} m\right)=\left(e^{*} m\right)^{*}\left(e^{*} n\right)=m^{*} n .
\end{gathered}
$$

On the other hand, for any $\operatorname{anti}(m) \in\{\operatorname{anti}(m)\}$, anti $(n) \in\{\operatorname{anti}(n)\}$, by Proposition $5(1)$, we have

$$
\begin{gathered}
\left(m^{*} n\right)^{*}\left[\operatorname{anti}(m)^{*} \operatorname{anti}(n)\right]=\left(m^{*} \operatorname{anti}(n)\right)^{*}\left(\operatorname{anti}(m)^{*} n\right)=\left[\left(m^{*} \operatorname{anti}(n)\right)^{*} n\right]^{*} \operatorname{anti}(m) \\
=\left[m^{*}\left(n^{*} \operatorname{anti}(n)\right)\right]^{*} \operatorname{anti}(m)=\left(m^{*} \text { neut }(n)\right)^{*} \operatorname{anti}(m)=\left(m^{*} e\right)^{*} \operatorname{anti}(m) \\
=m^{*} \operatorname{anti}(m)=\operatorname{neut}(m)=e . \\
{\left[\operatorname{anti}(m)^{*} \operatorname{anti}(n)\right]^{*}\left(m^{*} n\right)=\left[\operatorname{anti}(m)^{*} n\right]^{*}\left[m^{*} \operatorname{anti}(n)\right]=\operatorname{anti}(m)^{*}\left[\left(m^{*} \operatorname{anti}(n)\right)^{*} n\right]} \\
=\operatorname{anti}(m)^{*}\left[m^{*}\left(n^{*} \operatorname{anti}(n)\right)\right]=\operatorname{anti}(m)^{*}\left(m^{*} n e u t(n)\right)=\operatorname{anti}(m)^{*}\left(m^{*} e\right) \\
=\operatorname{anti}(m)^{*} m=\operatorname{neut}(m)=e .
\end{gathered}
$$

From this, using Theorem 6 and Definition 4 , we know that neut $\left(m^{*} n\right)=e$. Therefore, $m^{*} n \in S(e)$, i.e., $\left(S(e),{ }^{*}\right)$ is a sub groupoid.

Moreover, $\forall m \in S(e), \exists q \in S$ such that $q \in\{\operatorname{anti}(m)\}$. Applying Theorem $10(1)(2)(3), q^{*} n e u t(m) \in$ $\{\operatorname{anti}(m)\}$; and applying Theorem $10(5)$, neut $\left(q^{*}\right.$ neut $\left.(m)\right)=$ neut $(m)$.

Put $t=q^{*}$ neut $(m)$, we get

$$
\begin{gathered}
t=q^{*} \operatorname{neut}(m) \in\{\operatorname{anti}(m)\} \\
\operatorname{neut}(t)=\operatorname{neut}\left(q^{*} \operatorname{neut}(m)\right)=\operatorname{neut}(m)=e .
\end{gathered}
$$

Thus $t \in\{\operatorname{anti}(m)\}$, neut $(t)=e$, i.e., $t \in S(e)$ and $t$ is the inverse element of $m$ in $S(e)$.

Hence, $\left(S(e),{ }^{*}\right)$ is a subgroup of $S$.

(2) Let $x \in S\left(e_{1}\right) \cap S\left(e_{2}\right)$ and $e_{1}, e_{2} \in E(S)$. We have neut $(x)=e_{1}$, neut $(x)=e_{2}$. Using Theorem $6, e_{1}=e_{2}$. Therefore, $e_{1} \neq e_{2} \Rightarrow S\left(e_{1}\right) \cap S\left(e_{2}\right)=\emptyset$.

(3) For any $x \in S$, there exists neut $(x) \in S$. Denote $e=$ neut $(x)$, then $e \in E(S)$ and $x \in S(e)$.

This means that $S=\cup_{e \in E(S)} S(e)$.

Example 13. Table 13 represents a TA-NET-groupoid of order 5. And,

$$
\begin{gathered}
\operatorname{neut}\left(m_{1}\right)=m_{4}, \operatorname{anti}\left(m_{1}\right)=m_{1} ; \operatorname{neut}\left(m_{2}\right)=m_{3}, \operatorname{anti}\left(m_{2}\right)=m_{2} ; \\
\operatorname{neut}\left(m_{3}\right)=m_{3}, \operatorname{anti}\left(m_{3}\right)=\left\{m_{3}, m_{5}\right\} ; \operatorname{neut}\left(m_{4}\right)=m_{4}, \operatorname{anti}\left(m_{4}\right)=m_{4} ; \operatorname{neut}\left(m_{5}\right)=m_{5}, \operatorname{anti}\left(m_{5}\right)=m_{5}
\end{gathered}
$$

Table 13. Cayley table on $S=\left\{m_{1}, m_{2}, m_{3}, m_{4}, m_{5}\right\}$

\begin{tabular}{cccccc}
\hline$*$ & $\boldsymbol{m}_{\mathbf{1}}$ & $\boldsymbol{m}_{\mathbf{2}}$ & $\boldsymbol{m}_{\mathbf{3}}$ & $\boldsymbol{m}_{\mathbf{4}}$ & $\boldsymbol{m}_{\mathbf{5}}$ \\
\hline $\boldsymbol{m}_{\mathbf{1}}$ & $m_{4}$ & $m_{4}$ & $m_{1}$ & $m_{1}$ & $m_{1}$ \\
$\boldsymbol{m}_{\mathbf{2}}$ & $m_{3}$ & $m_{3}$ & $m_{2}$ & $m_{2}$ & $m_{2}$ \\
$\boldsymbol{m}_{\mathbf{3}}$ & $m_{2}$ & $m_{2}$ & $m_{3}$ & $m_{3}$ & $m_{3}$ \\
$\boldsymbol{m}_{\mathbf{4}}$ & $m_{1}$ & $m_{1}$ & $m_{4}$ & $m_{4}$ & $m_{4}$ \\
$\boldsymbol{m}_{\mathbf{5}}$ & $m_{2}$ & $m_{2}$ & $m_{3}$ & $m_{3}$ & $m_{5}$ \\
\hline
\end{tabular}

Denote $S_{1}=\left\{m_{1}, m_{4}\right\}, S_{2}=\left\{m_{2}, m_{3}\right\}, S_{3}=\left\{m_{5}\right\}$, then $S_{1}, S_{2}$ and $S_{3}$ are subgroup of $S$, and $S=S_{1} \cup S_{2}$ $\cup S_{3}, S_{1} \cap S_{2}=\emptyset, S_{1} \cap S_{3}=\emptyset, S_{2} \cap S_{3}=\emptyset$. 
Example 14. Table 14 represents a TA-NET-groupoid of order 5. And,

$$
\begin{gathered}
\operatorname{neut}(x)=x, \operatorname{anti}(x)=x ; \operatorname{neut}(y)=y,\{\operatorname{anti}(y)\}=\{y, v\} ; \\
\operatorname{neut}(z)=y,\{\operatorname{anti}(z)\}=\{z, v\} ; \operatorname{neut}(u)=u,\{\operatorname{anti}(u)\}=\{y, z, u, v\} ; \operatorname{neut}(v)=v, \operatorname{anti}(v)=v . \\
\text { Denote } S_{1}=\{x\}, S_{2}=\{y, z\}, S_{3}=\{u\}, S_{4}=\{v\}, \text { then } S_{1}, S_{2}, S_{3} \text { and } S_{4} \text { are subgroup of } S, \text { and } \\
\mathrm{S}=S_{1} \cup S_{2} \cup S_{3} \cup S_{4}, S_{1} \cap S_{2}=\emptyset, S_{1} \cap S_{3}=\emptyset, S_{1} \cap S_{4}=\emptyset, S_{2} \cap S_{3}=\emptyset, S_{2} \cap S_{4}=\emptyset, S_{3} \cap S_{4}=\emptyset .
\end{gathered}
$$

Table 14. Cayley table on $S=\{x, y, z, u, v\}$.

\begin{tabular}{llllll}
\hline$*$ & $x$ & $y$ & $z$ & $u$ & $v$ \\
\hline $\boldsymbol{x}$ & $x$ & $x$ & $x$ & $x$ & $x$ \\
$y$ & $u$ & $y$ & $z$ & $u$ & $y$ \\
$z$ & $u$ & $z$ & $y$ & $u$ & $z$ \\
$u$ & $u$ & $u$ & $u$ & $u$ & $u$ \\
$v$ & $u$ & $y$ & $z$ & $u$ & $v$ \\
\hline
\end{tabular}

Open Problem. Are there some TA-NET-groupoids which are not semigroups?

\section{Conclusions}

In this study, we introduce the new notions of TA-groupoid, TA-NET-groupoid, discuss some fundamental characteristics of TA-groupoids and established their relations with some related algebraic systems (see Figure 2), and prove a decomposition theorem of TA-NET-groupoid (see Theorem 13). Studies have shown that TA-groupoids have important research value, provide methods for studying other non-associated algebraic structures, and provide new ideas for solving algebraic problems. This study obtains some important results:

(1) The concepts of commutative semigroup and commutative TA-groupoid are equivalent.

(2) Every TA-groupoid with left identity element is a monoid.

(3) A TA-groupoid is a band if each element is idempotent (see Theorem 4 and Example 9).

(4) In a Tarski associative neutrosophic extended triplet groupoid (TA-NET-groupoid), the local unit element neut(a) is unique (see Theorem 7).

(5) The concepts of commutative TA-groupoid and WC-TA-groupoid are equivalent.

(6) In a TA-NET-groupoid, the product of two idempotent elements is still idempotent (see Theorem 12 and Example 12).

(7) Every TA-NET-groupoid is factorable (see Theorem 13 and Example 13-14).

Those results are of great significance to study the structural characteristics of TA-groupoids and TA-NET-groupoids. As the next research topic, we will study the Green relations on TA-groupoids and some relationships among related algebraic systems (see $[23,25,28]$ ).

Author Contributions: X.Z., W.Y. and M.C. initiated the research and wrote the paper, F.S. gave related guidance. All authors have read and agreed to the published version of the manuscript.

Funding: This research was funded by National Natural Science Foundation of China grant number 61976130.

Conflicts of Interest: The authors declare no conflict of interest. 


\section{References}

1. Dickson, L.E. Book Review: Éléments de la Théorie des Groupes Abstraits. Bull. Amer. Math. Soc. 1904, 11, 159-162. [CrossRef]

2. Clifford, A.H.; Preston, G.B. The Algebraic Theory of Semigroups; American Mathematical Society: Providence, RI, USA, 1961.

3. Holgate, P. Groupoids satisfying a simple invertive law. Math. Stud. 1992, 61, 101-106.

4. Howie, J.M. Fundamentals of Semigroup Theory; Oxford University Press: Oxford, UK, 1995.

5. Akinmoyewa, J.T. A study of some properties of generalized groups. Octogon 2009, 17, 599-626.

6. Suschkewitsch, A. On a generalization of the associative law. Transactions of the American Mathematical Society. 1929, 31, 204-214. [CrossRef]

7. Hosszu, M. Some functional equations related with the associative law. Publ. Math. Debrecen 1954, 3, $205-214$.

8. Maksa, G. CM solutions of some functional equations of associative type. Ann. Univ. Sci. Budapest. Sect. Comput. 2004, 24, 125-132.

9. Schölzel, K.; Tomaschek, J. Power series solutions of Tarski's associativity law and of the cyclic associativity law. Aequat. Math. 2016, 90, 411-425. [CrossRef]

10. Thedy, A. Ringe mit $\mathrm{x}(\mathrm{yz})=(\mathrm{yx}) \mathrm{z}$. Mathematische Zeitschriften. 1967, 99, 400-404. [CrossRef]

11. Phillips, J.D.; Vojtechovský, P. Linear groupoids and the associated wreath products. J. Symb. Comput. 2005, 40, 1106-1125. [CrossRef]

12. Pushkashu, D.I. Para-associative groupoids. Quasigroups Relat. Syst. 2010, 18, 187-194.

13. Weinstein, A. Groupoids: Unifying internal and external symmetry. A tour through some examples. Not. AMS 1996, 43, 744-752.

14. Kazim, M.A.; Naseeruddin, M. On almost semigroups. Alig. Bull. Math. 1972, 2, 1-7.

15. Shah, M.; Shah, T.; Ali, A. On the cancellativity of AG-groupoids. Int. Math. Forum 2011, 6, 2187-2194.

16. Stevanovic, N.; Protic, P.V. Some decomposition on Abel-Grassmann's groupoids. PU. M. A. 1997, 8, 355-366.

17. Shah, M.; Ali, A.; Ahmad, I. On introduction of new classes of AG-groupoids. Res. J. Recent Sci. 2013, 2, 67-70.

18. Mushtaq, Q.; Khan, M. Direct product of Abel-Grassmann's groupoids. J. Interdiscip. Math. 2008, 11, $461-467$. [CrossRef]

19. Mushtaq, Q.; Kamran, M.S. On LA-semigroups with weak associative law. Sci. Khyber. 1989, 1, 69-71.

20. Ahmad, I.; Rashad, M.; Shah, M. Some properties of AG*-groupoid. Res. J. Recent Sci. 2013, 2, 91-93.

21. Iqbal, M.; Ahmad, I.; Shah, M.; Ali, M.I. On cyclic associative Abel-Grassman groupoids. Br. J. Math. Comput. Sci. 2016, 12, 1-16. [CrossRef]

22. Iqbal, M.; Ahmad, I. On further study of CA-AG-groupoids. Proc. Pakistan Acad. Sci. A. Phys. Comput. Sci. 2016, 53, 325-337.

23. Zhang, X.H.; Ma, Z.R.; Yuan, W.T. Cyclic associative groupoids (CA-groupoids) and cyclic associative neutrosophic extended triplet groupoids (CA-NET-groupoids). Neutrosophic Sets Syst. 2019, 29, 19-29.

24. Smarandache, F. Neutrosophic Perspectives: Triplets, Duplets, Multisets, Hybrid Operators, Modal Logic, Hedge Algebras and Applications; Pons Publishing House: Brussels, Belgium, 2017.

25. Zhang, X.H.; Wu, X.Y.; Mao, X.Y.; Smarandache, F.; Park, C. On neutrosophic extended triplet groups (loops) and Abel-Grassmann's groupoids (AG-groupoids). J. Intell. Fuzzy Syst. 2019, 37, 5743-5753. [CrossRef]

26. Smarandache, F.; Ali, M. Neutrosophic triplet group. Neural Comput. Appl. 2018, 29, 595-601.

27. Golan, J.S. Semirings and Their Applications; Springer: Dordrecht, The Netherlands, 1999.

28. Zhang, X.H.; Borzooei, R.A.; Jun, Y.B. Q-filters of quantum B-algebras and basic implication algebras. Symmetry 2018, 10, 573. [CrossRef]

(C) 2020 by the authors. Licensee MDPI, Basel, Switzerland. This article is an open access article distributed under the terms and conditions of the Creative Commons Attribution (CC BY) license (http://creativecommons.org/licenses/by/4.0/). 